Review

\title{
Aqueous Adsorption of Heavy Metals on Metal Sulfide Nanomaterials: Synthesis and Application
}

\author{
Varney Kromah ${ }^{1,2}$ (1) and Guanghui Zhang ${ }^{1, *}$ \\ 1 School of Environmental Science and Engineering, Tianjin University, Tianjin 300350, China; \\ kromah820@gmail.com \\ 2 Department of Geology and Mining Engineering, Faculty of Engineering, University of Liberia, \\ Monrovia 1000, Liberia \\ * Correspondence: zgh@tju.edu.cn
}

Citation: Kromah, V.; Zhang, G. Aqueous Adsorption of Heavy Metals on Metal Sulfide Nanomaterials: Synthesis and Application. Water 2021, 13, 1843. https://doi.org/ 10.3390/w13131843

Academic Editor: Laura Bulgariu

Received: 18 May 2021

Accepted: 24 June 2021

Published: 1 July 2021

Publisher's Note: MDPI stays neutral with regard to jurisdictional claims in published maps and institutional affiliations.

Copyright: (c) 2021 by the authors. Licensee MDPI, Basel, Switzerland. This article is an open access article distributed under the terms and conditions of the Creative Commons Attribution (CC BY) license (https:// creativecommons.org/licenses/by/ $4.0 /)$.

\begin{abstract}
Heavy metals pollution of aqueous solutions generates considerable concerns as they adversely impact the environment and health of humans. Among the remediation technologies, adsorption with metal sulfide nanomaterials has proven to be a promising strategy due to their costeffective, environmentally friendly, surface modulational, and amenable properties. Their excellent adsorption characteristics are attributed to the inherently exposed sulfur atoms that interact with heavy metals through various processes. This work presents a comprehensive overview of the sequestration of heavy metals from water using metal sulfide nanomaterials. The common methods of synthesis, the structures, and the supports for metal sulfide nano-adsorbents are accentuated. The adsorption mechanisms and governing conditions and parameters are stressed. Practical heavy metal remediation application in aqueous media using metal sulfide nanomaterials is highlighted, and the existing research gaps are underscored.
\end{abstract}

Keywords: metal sulfide; nanomaterial; adsorption; heavy metal; aqueous media; transition metal sulfide; cationic exchange; surface complexation; electrostatic attraction

\section{Introduction}

Most heavy metals (HMs) are soft metals classified as chalcophiles, a group of elements with a specific affinity for soft chalcogenides-S, Se, and Te according to the Pearson acidbase concept. This high sulfide affinity for HMs has been exploited with the emergence of multiple metal sulfide adsorbents (MSAs) [1,2].

Most novel metal sulfides (MSs) and their nanocomposites (NCs) have the advantage of being composed of transition metals with outstanding affinities for many HMs. Transition metal sulfides (TMSs) contain numerous surface vacancies, defects, and reactive sites such as metal-edge sites, S-edge sites, and basal plane sites in their structures [3]. These imperfections allow the presence of copious adsorption active sites for removal mechanisms, including direct ion exchange, redox reaction, precipitation, surface complexation, and electrostatic attraction of HM cations that are capable of spanning and populating these interfaces. The novel synthetic MSs or their NCs, in general, are excellent adsorbents of HMs with direct surface activation. They are amenable to fine-tuning for specific properties such as controlling the interlayer spacing and layer thickness through cation exchange [4] and exfoliation/intercalation using suitable polar micromolecular solvent [5-7]. These processes make the MSs capable of capturing hydrated HMs with hydrated radii larger than the layer $d$-spacing of MSs [8]. The affinities for metals are enhanced by enlarging the interlayer spacing, allowing for HMs sequestration via coordination $[9,10]$, and ion exchange [11].

Many reviews have focused on research works conducted on the synthesis, properties, classifications, and applications of metal sulfide nanomaterials (MS-NMs). However, most are based on other applications $[3,12,13]$ rather than removing HMs from aqueous 
solutions. Lately, there has been a significant interest in MSAs for HMs removal from aqueous media. This rise is seen in the continuous increase in published papers as per Web of Science Database searches with keywords "metal sulfides and metal adsorption" (Figure 1A) and searching in the results with keywords "water or wastewater" (Figure 1B). Recent advances in the development and subsequent adsorption investigations of MS-NMs decontamination of aqueous media polluted with HMs utilizing adsorption strategies have not been thoroughly reviewed.
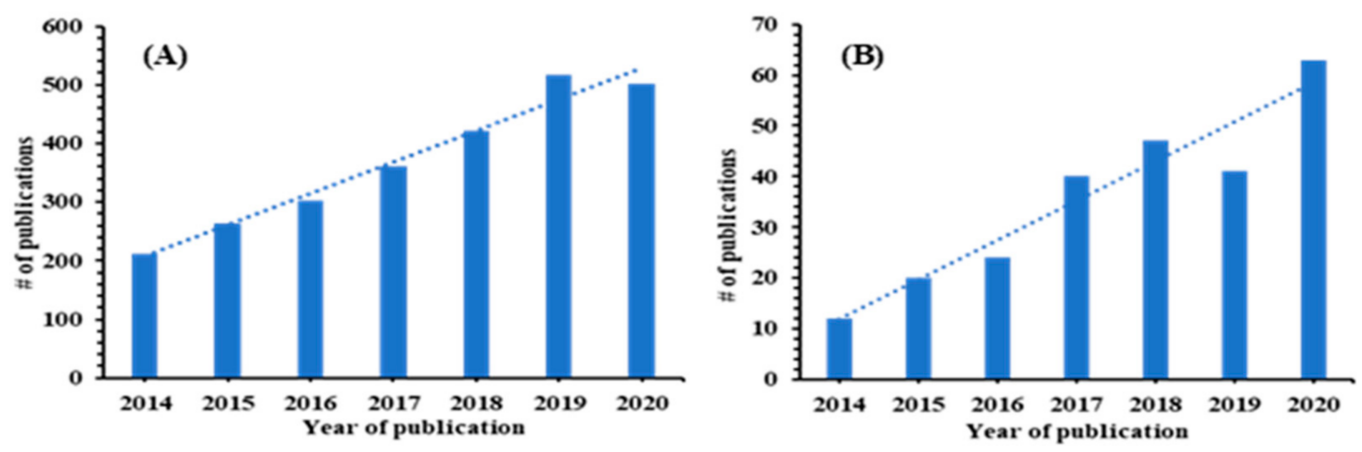

Figure 1. (A) Publication results in Web of Science using the keywords "Metal sulfide and metal adsorption". (B) Publications from searching in the results with keyword "Water and Wastewater".

Hence, this work is a systematic review of the state-of-the-art progress made in HMs sequestration from aqueous solutions by MS-NMs. Therefore, the aim of this review was to explore the application of MS-NMs for HM abatement from aqueous environments under ambient conditions, focusing on three main aspects: (1) MS-NM structures and preparation, (2) adsorption mechanisms and variables affecting adsorption performance of MS-NMs for HMs, and (3) major gaps and potential research requirements.

\section{Structures, Preparation, and Supports of MS-NMs}

MSs contain atom(s) of metal(s) chemically bonded to atom(s) of sulfur. The arrangement of atoms is critical in determining the structural stability of MSs with close-packed units in their structures. In order words, the bonds/interactions between the atoms and the ensuing structures are crucial in defining the properties of MSs. They account for their robust adsorption capacities and the possibility to enhance their adsorption characteristics further. Since their structures, compositions, and properties can be fine-tuned for meeting HMs' exceptional removal from water, MSs are widely synthesized. Requirements for enhancing the structures of MSs to meet environmentally friendly and cost-effective sequestration of metal pollutants from aqueous media include strategies to transform them into adsorbents of high selectivity, capacity, stability, and excellent recyclability. Traditional methods do not meet all these requirements. Hence, novel techniques have been developed to generate the requisite structures and properties of MSs, especially TMSs, for environmentally friendly abatement of HMs in water.

\subsection{Structures}

MSs occur with many stoichiometries and structures. The mono-MSs can be categorized as monosulfides (MS), disulfides $\left(\mathrm{MS}_{2}\right)$, trisulfides $\left(\mathrm{MS}_{3}\right)$, tetra-sulfides $\left(\mathrm{MS}_{4}\right)$, metal-rich sulfides (MxSy, $x>y)$, and sulfur-rich sulfides (MxSy, $x<y)$. The various metal sulfides and their examples are shown in Figure 2A. The monosulfides such as ZnS and $\mathrm{CdS}$ mainly crystalize in two motifs: the zinc blende structure in which the sulfide atoms pack in a cubic symmetry and the $\mathrm{Zn}^{2+}$ ions occupy half of the tetrahedral holes and wurtzite structure with hexagonal crystal symmetry, respectively [14,15]. Some disulfides are typically known for their two-dimensional (2D) layered graphene-shaped nanosheets (NSs) structures which have been utilized for many purposes [16]. The disulfides follow the $\mathrm{CdI}_{2}$ system (1T phase). In this system, the metals occupy all of the octahedral holes in 
the alternating layers structures, with the sulfide anions forming a hexagonal close-packed lattice. Other disulfides have the $\mathrm{MoS}_{2}$ structure with trigonal prismatic structure $(2 \mathrm{H}$ and $3 \mathrm{R}$ phases) [17] depending on the atomic arrangement and interlayer stacking. The 1T, 2H, and $3 R$ phases have one, two, and three sandwich layers, respectively (Figure 2B,C), and are transformable to each other via annealing, exfoliation, or other means $[18,19]$. While the $1 \mathrm{~T}$ and $3 \mathrm{R}$ phases, which are seldom seen in nature, are metallic because of the migrant electrons, the $2 \mathrm{H}$ phase is the naturally found thermodynamically stable semiconductor [20]. Disulfide structures containing two sulfide ions in each of the octahedral interstices in the cubic motif follow the high symmetric pyrite structure [12]. The trisulfide $\mathrm{MoS}_{3}$ and some metal-rich or sulfur-rich MSs can be layered amorphous substances with many pores in their structures [21-23].

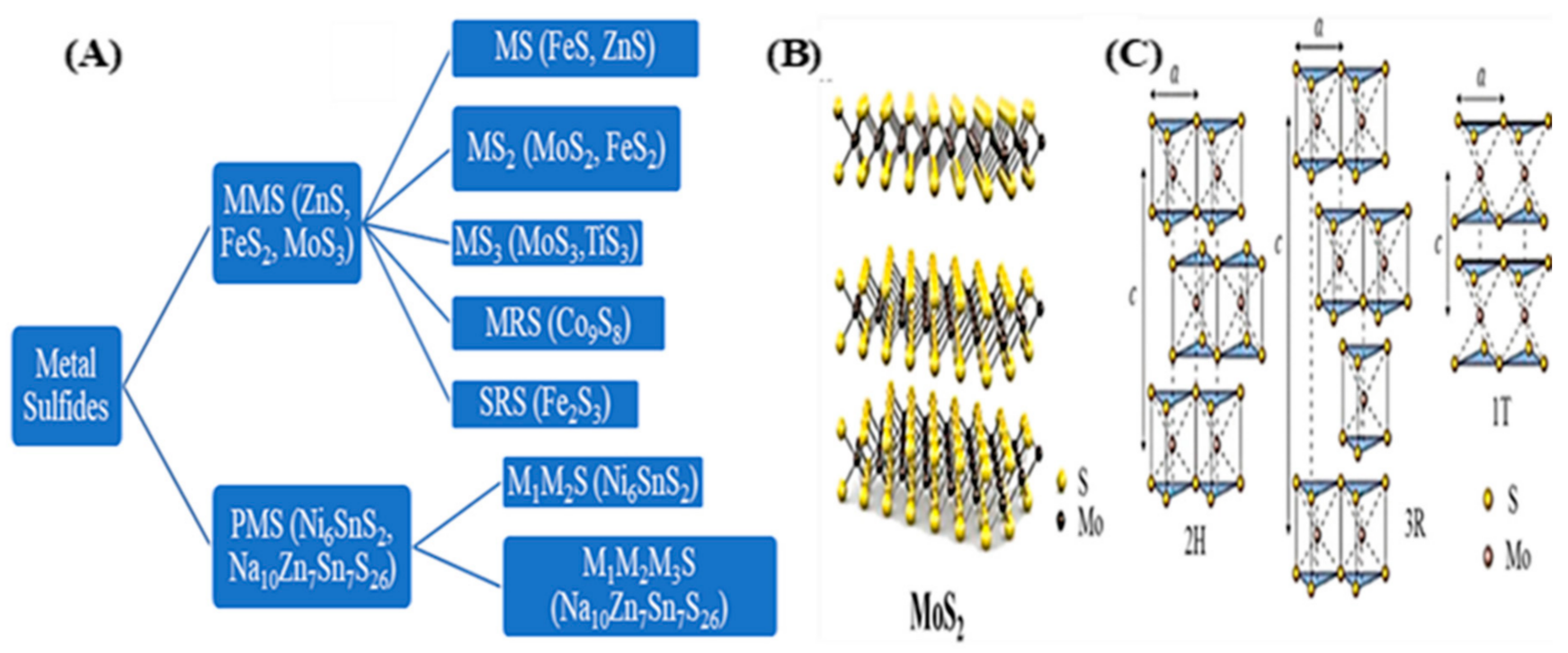

Figure 2. (A) Classification and examples of metal sulfides; (B) structure and (C) three phases of $\mathrm{MoS}_{2}$. MMS = monometal sulfides; PMS = polymetal sulfides; $\mathrm{MS}=$ monosulfides; $\mathrm{MS}_{2}=$ disulfides; $\mathrm{MS}_{3}=$ trisulfide; $\mathrm{MRS}=$ metal-rich sulfides; SRS = sulfide-rich sulfides; $\mathrm{M}_{1} \mathrm{M}_{2} \mathrm{~S}=$ ternary sulfide; $\mathrm{M}_{1} \mathrm{M}_{2} \mathrm{M}_{3} \mathrm{~S}=$ quaternary sulfide. Figure $2 \mathrm{~B}, \mathrm{C}$ were adapted from Xia et al. [24]. Copyright 2018, Elsevier.

Although MSs contain numerous reactive sites [3], the amount of exposed active sites is critical for achieving efficient adsorption. For example, the active S-sites in some MS-NCs are bridging $\mathrm{S}_{2}{ }^{2-}$ or apical $\mathrm{S}^{2-}$ species, having more electron binding energies than other active sulfide atoms [25]. However, these sites are active only when the S-sites consisting of unsaturated and interfacial $S$ atoms are exposed $[5,26]$. This observation explains why moderate deposition of exfoliated units on active sites promotes pollutants salvaging from aqueous solutions, unlike excess loading of the units, which completely covers the reactive sites [25]. HM ions can attack the numerous exposed bridging sulfide groups forming the S-edge sites in MS structures, converting them to metal-loaded terminal sulfide groups [27].

In contrast, there exists few bridging $S_{2}{ }^{2-}$ and apical $S^{2-}$ because of the limited number of unsaturated sulfide atoms in bulk $\mathrm{MoS}_{2}$ nanocrystals [28]. However, delamination or exfoliation reduces the number of layers and, coupled with the integration of metal elements to raise the number of active S-sites [29], can enhance adsorption. In general, the structural arrangements and imperfections in MS-NMs structures allow for the requisite cations to reside and be attached in these vacancies [30].

For removing HMs from aqueous media, the essential MSs include sulfides of transition metals such as zinc [14,15], copper [31,32], cobalt [21,22], iron [33-35], and cadmium $[14,36,37]$. MSs contain localized or migratory sulfide $3 \mathrm{~d}$ electrons or both, exhibiting hybridization with sulfide $3 \mathrm{~s}$ and 3 p orbitals, stabilizing the closest cation neighbors in the trigonal pyramidal, octahedral, tetrahedral, and other configurations in the anion arrays $[30,38]$. These configurations facilitate the formation of metal-metal and sulfur-sulfur 
covalent bonds. The increased covalency and polarization may support layered sheet structures with Van der Waals forces between the sheets [3,34,39]. The atomic arrangements in MSs are usually close-packing combinations, governed by ionic size, charge, and electron configuration $[30,40]$. However, the entire structure may not display a continuous close packing arrangement. A significant number of sulfides show close-packed units (blocks and rods) in groups connected to nearby structures by interfaces with cuts in a dense arrangement of anions faces that are differently oriented [30].

\subsection{Synthesis}

Several techniques have been introduced to synthesize and control features of MSNMs and their NCs [3]. Usually, two general strategies are involved: a top-down approach (in which bulk structures are disintegrated into few-layers or monolayer sheets) and bottomup methods (with which the build-up of an NM atom by atom or layer by layer is achieved). While the bottom-up approach's benefits are the low cost, scalability, and better uniformity of the product, the top-down strategy's advantage is its provision of better control. The conventional synthetic methods for producing MSAs generate bulk substances that exhibit inherent limitations, including inert basal planes [41] and low surface areas [42,43]. The novel synthetic technologies have proven to be promising for fabricating MSAs with more exposed active sites and are among the primary preparation methods for generating a wide range of nano-/micro-structured MSAs. In general, the strategies applied in these new synthetic techniques for tuning MSs to achieve required characteristics include surface adjustment, ligand modulation, solvation regulation during crystal formation, and physical grinding. Table 1 presents some of the methods of MS synthesis and their peculiarities.

Table 1. Methods of synthesis of MSs and their merits, demerits, and product quality.

\begin{tabular}{|c|c|c|c|c|}
\hline Synthetic Techniques & Merits & Demerits & Product Quality & Reference \\
\hline \multicolumn{5}{|c|}{ Top to bottom approaches } \\
\hline Mechanical exfoliation & Facile synthesis & Low productivity & $\begin{array}{l}\text { Perfect surface; } \\
\text { high crystallinity }\end{array}$ & {$[12,44]$} \\
\hline L.P./chemical exfoliation & $\begin{array}{l}\text { Facile synthesis with high-yield; } \\
\text { generally single-layer products }\end{array}$ & $\begin{array}{l}\text { Strict operating environment; } \\
\text { long reaction times }\end{array}$ & $\begin{array}{l}\text { Small size and } \\
\text { Few-layers thickness }\end{array}$ & {$[3,12,44]$} \\
\hline Ball milling & $\begin{array}{l}\text { Low cost, scalable, facile synthesis, } \\
\text { relatively low cost, high productivity }\end{array}$ & $\begin{array}{l}\text { Process-induced damages } \\
\text { such as irregular } \\
\text { shape product }\end{array}$ & More crystal defects & {$[45,46]$} \\
\hline Electrospinning & $\begin{array}{l}\text { Controlled formation of complex } \\
\text { structures; a variety of fiber size (from } \\
\text { submicron to nanometer diameters); } \\
\text { flexible materials with a variety } \\
\text { of functionalities }\end{array}$ & $\begin{array}{l}\text { High temperatures; expensive } \\
\text { to produce large diameter and } \\
\text { challenging to generate } \\
<10 \mathrm{~nm} \text { diameter fibers }\end{array}$ & Highly rough surfaces & {$[12,47]$} \\
\hline \multicolumn{5}{|c|}{ Bottom-up techniques } \\
\hline $\begin{array}{l}\text { Chemical vapor } \\
\text { deposition }\end{array}$ & $\begin{array}{l}\text { Adjustable thickness; considerable area } \\
\text { growth; rapid reaction rate; flexible } \\
\text { design and easy incorporation of new } \\
\text { technology to existing producing unit }\end{array}$ & $\begin{array}{l}\text { High-temperature } \\
\text { requirement; complex process; } \\
\text { usually toxic, explosive, } \\
\text { corrosive, and } \\
\text { costly precursors }\end{array}$ & High crystal quality & {$[3,12,44]$} \\
\hline $\begin{array}{l}\text { Hydrothermal } \\
\text { (solvothermal) synthesis }\end{array}$ & $\begin{array}{l}\text { Easy to operate; ability to synthesize } \\
\text { unstable substances near the melting } \\
\text { point; large crystals of high quality. }\end{array}$ & $\begin{array}{l}\text { High energy consumption and } \\
\text { cost of equipment; relatively } \\
\text { long production cycle }\end{array}$ & Numerous defects & {$[3,12,44]$} \\
\hline Cation exchange & $\begin{array}{c}\text { Easily, efficiently, and morphologically } \\
\text { tuned products; precise control of the } \\
\text { NP phase; rapid reaction rates; } \\
\text { high yield }\end{array}$ & $\begin{array}{l}\text { Relative high cost of } \\
\text { some chemicals }\end{array}$ & Numerous defects & {$[12,38]$} \\
\hline
\end{tabular}

\subsubsection{Top-Down Approach}

These techniques begin with a bulk material that is disintegrated into a few layers or monolayers [48]. In other words, it refers to successively slicing the bulk material into micro/nano-sized particles. To generate nano-sized structures, the top-down technique requires lateral patterning of bulk materials using either subtractive or additive processes [49]. 
Therefore, modern top-down NM synthesis methods may be divided into two groups: (1) transferring a computer-generated design to a bigger piece of bulk material and then physically removing material to produce a nanostructure and (2) rearranging or adding components to a substrate [50]. Photolithographic and lithographic methods are the most often used techniques in top-down approaches. Despite their affordability and speed, photolithographic technologies' resolution is limited by optical diffraction. Although lithographic methods enable the creation of ordered nanostructured arrays with high resolution and excellent control over particle shape and spacing, their output is low, and the process is slow when compared to a parallel technique (such as photolithography), which patterns the entire surface at once [50]. In general, the major drawbacks of topdown techniques are the development of imperfections in processed materials, high cost (lithographic processes), requirement of high surface finished materials, and longer etching times [49]. For MS-NM synthesis, the process includes physical and chemical routes including electrospinning, ball milling, and exfoliation. These are discussed below.

\section{Mechanical Exfoliation}

Sheets or flakes with few defects can be isolated from natural bulk $\mathrm{MoS}_{2}$ [51,52] and deposited on $\mathrm{Si} / \mathrm{SiO}_{2}$ substrate via the use of adhesive tape, which when released causes the MS to spread on the substrate surface due to the van der Waals forces $[12,44]$. This method yields thin $\mathrm{MoS}_{2}$ sheets of layers ranging from 1 to 5 but repeating the procedure yields flakes of different sizes, forms, and layer counts [53]. Despite the NSs obtained from scotch tape exfoliation having a near-perfect surface and high crystallinity, the main disadvantages are poor yield, limited surface defects, and the need to switch to a different substrate for future use [12,44].

\section{LPE}

It is known that the surface atoms in bulk solids play subordinate roles during adsorption. In contrast, thin-film MS-NMs have excellent absorption properties [9,10]. MSs in a solution can be exfoliated by mechanical approaches and ionic intercalation (chemical exfoliation) [12]. Exposure to many active sites by exfoliation in multiple layers or a single layer using ultrasonic LPE can easily be done [5]. For example, bulk MoS $\mathrm{x}_{\mathrm{x}}$ obtained by thermal decomposition of $\left(\mathrm{NH}_{4}\right)_{2} \mathrm{MoS}_{4}$ can be exfoliated in a suitable polar micromolecular solvent into monolayers or individual nanoflakes using ultrasonic radiation [6,7]. This process creates a force greater than the Van der Waals attraction between the layers, causing the bulk structure to crumble and be sliced into single-layer nanotubes that can easily be dispersed in polar micromolecular solvents. The criteria for selecting a surfactant or solvent are based on the similarity between the liquid's surface tension and the absorbent surface's free energy [54]. LPE results in high exfoliation success on materials with low surface energy and can prevent agglomeration of MS NSs [55] in contrast to mechanical exfoliation, where much of the resulting MSs are multilayer structures, which still blocked the efficient active sites in comparison with that in the well-dispersed single-layer structure [3].

The thickness of the single-layer NSs is typically in sub-nanometers, which increases the number of active sites exposed [6]. However, the thickness and sizes may be in a range of sub-nanometers [56]. Therefore, centrifugation at different speeds may be required to obtain more uniform size. Although LPE produces 2D MS NSs on a large scale, creating flakes of various shapes, sizes, and layers compared to other exfoliation techniques, it is a time-consuming process that creates a lower quality product and leaves the original nanostructure preserved after exfoliation [12,44].

During chemical exfoliation or ion intercalation, a solution of $\mathrm{Li}^{+}$ions is mixed with polar micromolecular solvents to destroy the original $2 \mathrm{H}-\mathrm{MoS}_{2}$ (with only active edges) with a trigonal-prismatic structure forming a $1 \mathrm{~T}$ octahedral filled phase with both active edge and basal sites [57]. The intercalated Li atoms weaken the bonds between $\mathrm{MoS}_{2}$ layers. Reacting the intercalated lithium-MoS 2 with excess water separates the layers 
essentially into monolayers $[3,56]$ but damages the structure of the NSs due to loss of the semiconducting $2 \mathrm{H}$ phase during the intercalation [58].

\section{Electrospinning}

Electrospinning is a technique for producing nanofibers in which electrical energy is used to make charged filaments from a polymer solution or melt with a fiber diameter of several hundred nanometers. Several MS-NMs have been successfully synthesized using the electrospinning technique $[13,39,59]$. The treated MS nanofiber has a high surface to volume ratio and high porosity, which makes it versatile in terms of surface properties, excellent mechanical properties, self-standing structure, and stable sulfur and HM interactions, rendering it ideal for use as an absorbent for remediation of HMs in aqueous solution [36]. The supporting material has a significant effect on the properties of the MS-NMs obtained by electrospinning. They may provide excellent structure, morphology, and surface properties leading to outstanding absorption functionalities of the adsorbent $[36,60]$.

\section{Ball Milling}

Ball milling is used to synthesize NCs, optimize structural composition, improve material reactivity and uniform spatial distribution of elements through mechanical activation, and prevent the problem of minor admixture formation during air cooling after sintering at high temperatures due to phase instability [61]. This process causes new surface and crystal abnormalities through physical and chemical reactions that change the reaction particles' properties and accelerate the reaction rate [35]. This inexpensive, facile, and scalable mechano-chemical path generates nm-sized hybrids with effective enlargement of the surface area and pore volume [62]. Ball milling induces a rough surface on the synthetic products, which accounts for the high adsorption capacities [33,35].

\subsubsection{Bottom-Up Strategy}

In bottom-up synthesis approaches, the nanostructures are deposited onto the substrate by assembling atoms generating crystal planes that are further stacked onto each other, leading to the synthesis of the nanostructures. In other words, the building blocks are added to the substrate to form the nanostructures [48]. The most prevalent are bottom-up manufacturing procedures based on the use of a templating substrate, such as chemically or topologically patterned surfaces, inorganic mesoporous structures, and organic supramolecular complexes [50]. This procedure involves the controlled segregation of atoms or molecules with nanostructures (2-10 $\mathrm{nm}$ in size) being formed from them. In general, there are two types of bottom-up approaches: synthesis of gaseous and liquid phases, and liquid phase production [49]. Even though bottom-up chemical synthesis has progressed to an astounding level of sophistication, current capacity to produce nanostructured materials from these methods are limited [63]. Some of these approaches as applied to MS-NMs are discussed below.

\section{Cation Exchange}

Metal chalcogenides with morphological and structural properties as heterostructures [4,64], the core and shell structures [65], and the metastable phase [66], which are difficult to achieve by conventional synthetic means, are now freely produced by the cation exchange process [38]. Since MS materials have different solubility constants $\left(K_{s p}\right)$ in water, they can be transformed via cation exchange into one another. The provision of a selftemplating [67] and easily controllable mechanism to create the multilateral hierarchical structures [68] renders this technique invaluable. MS-NMs can be fabricated readily by inserting the respective metal ions in the precursor MSs synthetic system [15]. The NMs formed by this process are robust adsorbents for HMs remediation, exhibiting high adsorption efficiencies and capacities due to their inherent cation exchange characteristics [69] even in multiple HM polluted aqueous media [15]. The mutual cation exchange properties 
of HMs can engender their separation via fractional or sequential adsorption on the MSNMs, with the metal having the most stable sulfide separating first [15]. This fractional or sequential cation exchange could be used to produce MSs in the same order as the manner of their separation. Since ion exchange leads to hollowing or tunneling of solid precursor wires, rods, and spheres without destroying the morphologies and structures [12], the original stability of MSs may be retained in the cation exchange-generated MSs. In general, the cation exchange preparation of MSs is governed by lattice structure stability [70] and defects in the crystal structure $[71,72]$ of the precursor sulfide.

Hydrothermal (Solvothermal) Synthesis

The Hydro-/solvo-thermal technique is used to synthesize a defect-rich product to allow exposure of more active sites. A solvothermal process is a hydrothermal approach with an organic solvent instead of water being used as a precursor solvent. This technique is a simple tool for making MS products with controlled structural properties [73] by reacting the appropriate metal and sulfur precursors under high temperature and pressure conditions. The efficiency of intercalation and stability of the $1 \mathrm{~T}$ phase of the $\mathrm{MoS}_{2}$ produced is contingent on the type of solvent used. Li et al. [18] synthesized $\mathrm{MoS}_{2}$ with the first step using water to produce a $1 \mathrm{~T} / 2 \mathrm{H}$ mixed phase of $\mathrm{MoS}_{2}$ consisting of $25 \% 1 \mathrm{~T}$ phase and the secondary solvothermal reaction obtaining pure $1 \mathrm{~T}-\mathrm{MoS}_{2}$ via ethanol, which was stable in air for over after 360 days and maintaining the same widened interlayer spacing as the $\mathrm{MoS}_{2}$ mixture.

The percentage of MS-NP detected in the composite may not depend on the amount added during the composite's hydrothermal preparation. Increasing the dosage of precursor only slightly changed the concentration of the core material [74], implying a certain amount of MS-NP may be required to saturate the support after which it is no longer absorbed. Additionally, the hydrothermal design can generate an abundance of unsaturated $\mathrm{S}$ atoms in disordered structures and tune the intrinsic adsorption efficiency. MS-NCs with a low surface area may still exhibit high uptake capacity [74], indicating more active sites were introduced by the synthetic method and the support.

Chemical Vapor Deposition

Precursors (usually molybdenum trioxide $\left(\mathrm{MoO}_{3}\right)$ or Mo metal and organic sulfides, respectively) containing Mo and S decompose, and the Mo and S atoms then combine via chemical reactions to form a $\mathrm{MoS}_{2}$ layer on the substrate, usually at temperatures between 700 and $1000{ }^{\circ} \mathrm{C}$, in the Chemical Vapor Deposition (CVD) process [12,54]. However, the temperature range is reduced to $150-300{ }^{\circ} \mathrm{C}$ with a modified version of $\mathrm{CVD}$, called the Plasma Enhanced CVD (PECVD) technique, which allows the deposition of NMs on plastic and flexible substrates [75]. NMs prepared by the CVD technique exhibit various tunable properties, including effective control of the active site, thickness, and size during NS growth due to changes in CVD parameters and conditions [44,76,77]. In particular, hydrogen gas is used to accelerate the reaction between sulfide precursors such as diethyl sulfide and Mo precursors, including $\mathrm{MoCl}_{5}$, and facilitate the formation of single-layer MSNPs few atoms thick with a large surface area $[53,78,79]$. Sulfur vapor is rarely composed of one atom, so the flow rate is slow, but with hydrogen sulfide obtained by adding hydrogen, the flow is fast, resulting in the rapid decomposition of sulfur precursors and the formation of MS-NMs with more S defects [3]. Although the NMs synthesized via CVD are crystalline, the complex operational processes limit largescale production [44].

\subsection{Functions and Types of Support/Stabilizing Materials for MS-NMs}

Due to the inherent difficulties in removing HMs from aqueous media using MSAs, many substances have been studied and utilized as supports or stabilizers to enhance efficient adsorption. 


\subsubsection{Functions of Support/Stabilizing Materials for MSs}

The various supports for core NMs are employed for diverse reasons. However, one primary function of supports for MS-NMs is giving the core material stability in the air. Many MSs, especially FeS, are easily oxidized in the air and consequently require support to limit or prevent the oxidation $[34,80,81]$. Another critical reason for the use of a support for some nanoparticles of MSs is that they agglomerate rapidly in water, thereby having limited interaction with the targeted HMs [82-84]. Suitable support is usually needed to stabilize them for efficient adsorption in aqueous solutions. A third crucial necessity for adding support to MS-NMs is for the particles to separate from the water quickly without complex filtration or centrifugation systems. This separation is usually accomplished by the use of magnetic support $[73,85]$. Additionally, most supporting materials contain numerous active sites, and when added to MS-NMs, they synergistically enhanced the adsorption of the HMs [81,86-88].

However, the use of support materials may have some disadvantages. For example, ZVI has the drawback of becoming oxidized readily by aqueous dissolved oxygen, which consumes electrons intended for the target contaminants, resulting in inefficiency [89]. Thus, ZVI becomes an inadequate electron donor, promoting surface iron oxide deposition during the activation of iron (II) ions [90]. Secondly, the addition of support can incur additional costs. The addition of magnetic support to MS-NMs to aid in the easy separation of adsorbent from water may be cost-intensive for largescale applications. Additionally, the support may interfere with the adsorption process, limiting removal efficiency [34].

\subsubsection{Types of Supporting Materials}

In general, all supporting materials for MSAs can be classified as either organic or inorganic.

\section{Organic Support}

Organic supports or stabilizers are abundantly used in NCs due to their many advantages. They usually contain smaller micropore volume, higher specific surface area, abundant functional groups and are low cost $[81,86-88]$. These supporting materials generally have the merits of excellent water stability and high mechanical strength [91,92], making them invaluable to the adsorption process. Some are noted for their biodegradability, non-toxicity, abundant source, [86], an excellent affinity for HM [93], and are modification coats for metal NPs in preventing aggregation [83,84]. Notable organic supports for MSs includes biochar [88], chitosan [91], and carboxymethylcellulose CMC [92]. In most cases, the organic supports serve as a substrate for the MS NPs to be deposited on or can be used to coat the surface of the adsorbents via the various preparation methods.

\section{Inorganic Support}

In general, inorganic supports show excellent thermal, chemical, and mechanical stabilities. For MSs, the most prominent inorganic supports include carbon materials, ZVI, and metal oxides. The carbon materials may consist of graphene oxide and other carbon NMs such as carbon nanotubes and nanofibers. Based on their outstanding surface, mechanical, thermal, and optical properties, carbon NMs are widely utilized in many fields, including environmental remediation, energy generation, and water treatment. Inorganic carbon NMs generally exhibit high mechanical strength and thermal stability for MS-base materials, providing mechanic supports to prevent aggregation [74,94]. ZVI adsorbents, on the other hand, have many advantages, including low solid waste product, in situ application, robust removal efficiency independent of changes in the quantity of water treated [95], and safe, environmentally sustainable, and cost-effectiveness for HM species [96,97]. Hence, ZVI can be successfully employed to activate and serve as support for FeS. The primary metal oxides used as supports for MSs include $\mathrm{SiO}_{2}, \mathrm{Al}_{2} \mathrm{O}_{3}$, and $\mathrm{Fe}_{3} \mathrm{O}_{4} \cdot \mathrm{SiO}_{2}$ amorphous NMs are used to support MSs due to their high porosity, large surface area, stable structure, and flexibility [60], which ensure immobilization, longevity, 
and high recovery. Besides its porous structure and high stability, $\mathrm{Al}_{2} \mathrm{O}_{3}$ exhibits strong chemical and thermal stability, rendering it suitable for preventing MS aggregation and oxidation [82]. Although $\mathrm{Fe}_{3} \mathrm{O}_{4}$ adsorbents show high adsorption efficiencies, their major significance is their ability to separate easily from the supernatant after adsorption on their own or via the application of external magnetic fields [73,85].

\section{Motivations for Choosing MS-NMs over Bulk Materials and Their HM Adsorption Mechanism}

\subsection{Motivations for Choosing MS-NMs over Bulk Materials for HM Removal from Water}

NMs, which have a particle size range of $1 \mathrm{~nm}$ to $100 \mathrm{~nm}$, have been employed to overcome the shortcomings of conventional adsorbents in recent decades [98]. Recently, MS-NMs have been used in environmental remediation. They have been used to remove contaminants like dyes [99], heavy metals [62], pharmaceuticals [81], and radionuclides [80]. However, due of the inherent drawbacks of bulk materials, nanosized materials are receiving a lot of attention. Due to their fine particle size, large surface area, high surface-to-volume ratios, robust sensitivity and reactivity, high adsorption capacity, ease of functionalization, and regulated deliverability, nanoparticles including MS-NMs have shown tremendous promise for treating polluted aquatic systems as compared to bulk particles $[82,100]$. The binding of inorganic shells and organic molecules to the surface of MS-NMs stabilizes and inhibits the oxidation of nanoparticles [49]. Nanosized MS particles can be composited with other NMs such as carboxymethyl cellulose (CMC) [101], chitosan [91], carbon NMs [102], biochar [87] and ZVI [33] to form NCs with highly improved adsorption functionalities. Most of these supporting structures are locally available, cheap and abundant, and render their MS-NCs inexpensive [86].

NMs are efficient and cost-effective for the fast removal and recovery of metal ions from wastewater effluents due to their large surface areas and excellent magnetic characteristics [49]. The careful balance between the energy from the polar charges, surface area, and elastic deformation results in the diverse shapes and morphologies crucial to the characteristics and efficiency of MS-NMs [82]. Furthermore, the surface functions give locations for the absorption of particular or selective ions, hence improving their removal efficiency [98].

\subsection{Adsorption Mechanisms of HMs on MS-NMs}

The adsorption process of HMs on MS-NMs ensues via physical and chemical interactions between an adsorbent and an adsorbate and are modified by the reactive environment $[33,87,102]$. Ionic or covalent bonds form during chemical adsorption, making the process exceedingly specific. Monolayer adsorption will arise from the irreversible chemical interaction [103]. Contrastingly, the physical process involves weak Van der Waals forces between the adsorbate and the adsorbent in a reversible process [103]. Physical adsorption may involve monolayer or multilayer deposition, which is not specific. Some of the specific adsorption mechanisms that explain the attachment of metal ions to NMs include redox reaction, complexation, intraparticle diffusion, surface adsorption, precipitation, electrostatic interaction, and ion exchange and are illustrated in Figure 3.

Based on their redox potentials, distinct HMs' adsorption mechanisms on MS-NMs may be classified as adsorptive removal or redox removal [44]. The adsorptive mechanisms dominate when the heavy metal redox couples are lower than that of $\mathrm{MoO}_{4}{ }^{2-}$ and $\mathrm{SO}_{4}{ }^{2-} / \mathrm{MoS}_{2}$ pair $[58,104]$. Otherwise, the adsorption follows redox or adsorptive removal. The process is seen in Figure 4B. MS-NMs could be oxidized via electron loss, which are involved in the reduction of the HMs [105]. The process is illustrated for the adsorption of $\mathrm{Ag}^{+}$by $\mathrm{MoS}_{2}$ nanosheets in Figure 4A. The adsorption of $\mathrm{Cr}^{6+}$ from water by reduction to $\mathrm{Cr}^{3+}$ by MS-NMs is a classic example of redox removal of HMs by MS-NMs. The adsorption follows the equations such as: $\mathrm{HCrO}_{4}{ }^{-}+6 \mathrm{H}^{+}+3 \mathrm{e}^{-} \leftrightarrow[\mathrm{Cr}(\mathrm{OH})]^{2+}+3 \mathrm{H}_{2} \mathrm{O}$ as chromium is usually found as oxyanions in these solutions. 


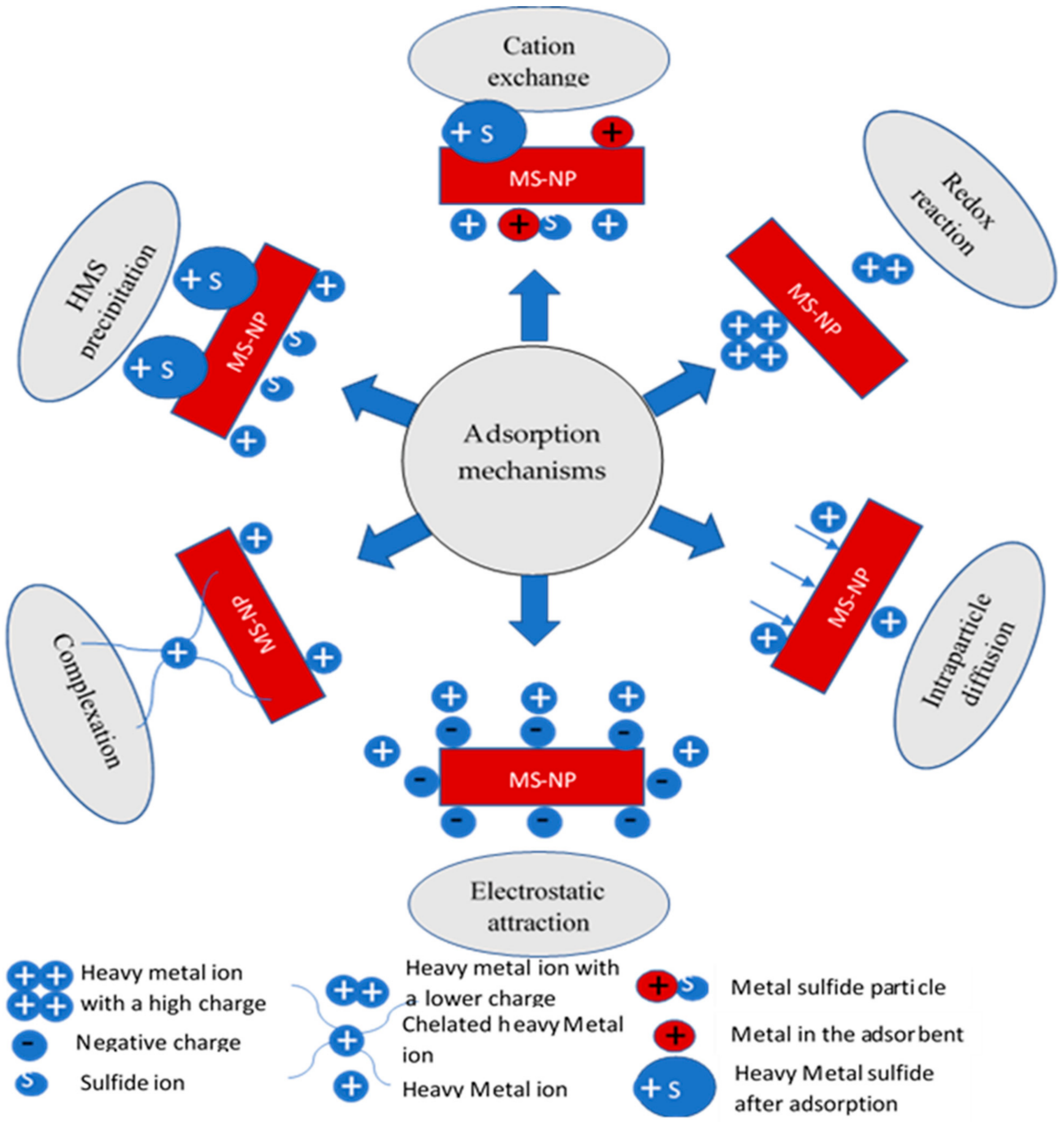

Figure 3. Various adsorption mechanisms of metal ion adsorbate on metal sulfide nanoparticle (MN-NP).

To fully comprehend the mechanism of heavy metals adsorption on MS-NMs, adsorption isotherms, kinetics, and thermodynamics may all be employed. The chemical composition and properties of the material appear to impact adsorption processes on nanoadsorbents. Besides, parameters such as solution $\mathrm{pH}$, initial HM concentration, and contact time have an impact on the adsorption process. These parameters and the specific adsorption mechanisms of HM adsorption on MS-NMs are discussed in detail in the next section. 
(A) Adsorption

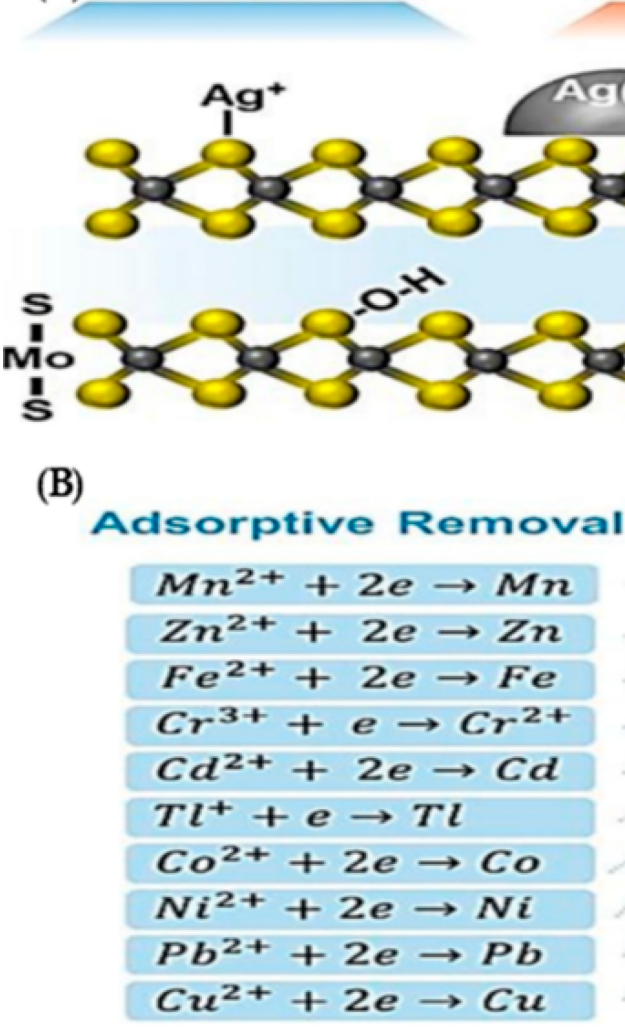

Antioxidation

$\mathrm{H}_{2} \mathrm{O}_{2}+2 \mathrm{H}^{+}+2 e \rightarrow 2 \mathrm{H}_{2} \mathrm{O}$
$-\mathrm{OH}+e \rightarrow \mathrm{OH}^{-}$
$\mathrm{O}_{3}+2 \mathrm{H}^{+}+2 e \rightarrow \mathrm{O}_{2}+\mathrm{H}_{2} \mathrm{O}$
Redox Reaction

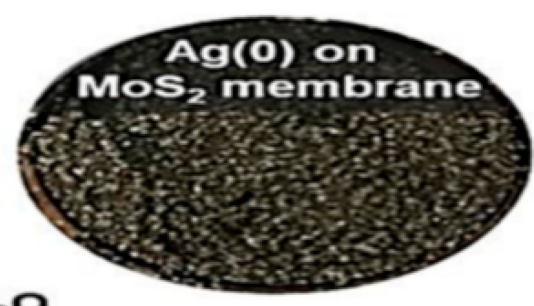

$\mathrm{MOO}_{4}^{2-}$ and oxidized's species

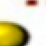

$\cdots \cdot D$ 
and oxidation and increase recovery efficiency. However, some supports may reduce the removal efficiency of the adsorbent [34]; therefore, suitable materials that do not adversely affect adsorption efficiency are required.

(A)
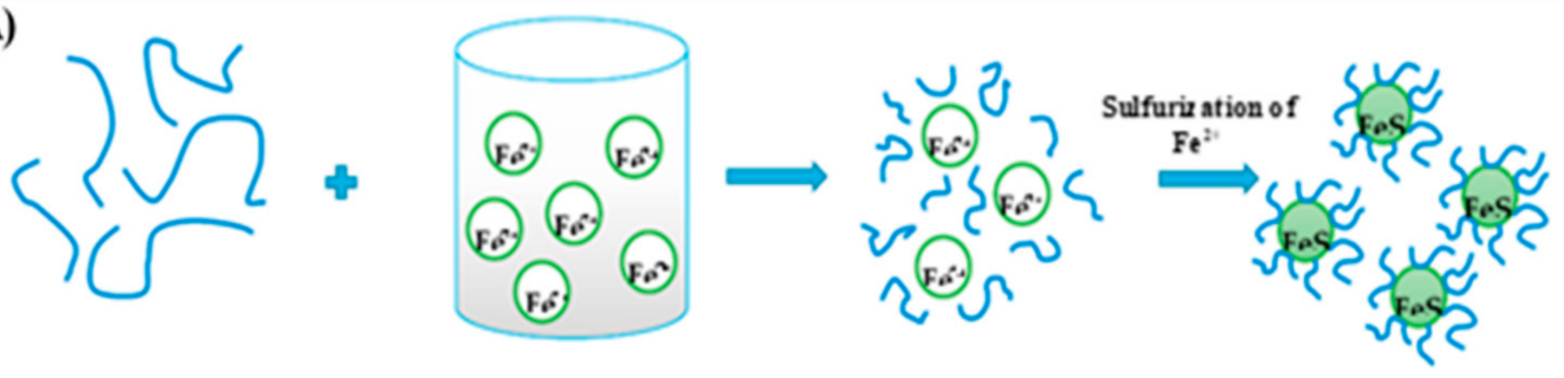

Stabilizer

Fe* solution

Stabilizer-Fe*

Stabilized-FeS

(B)

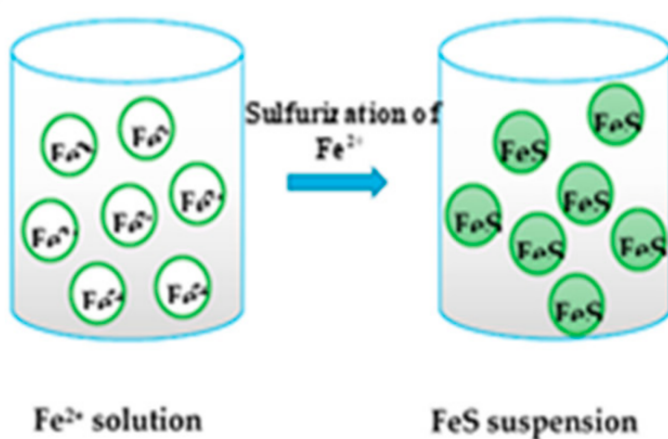

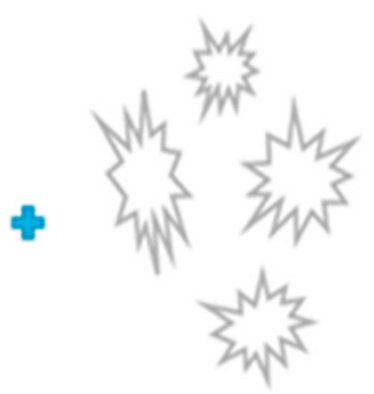

Supported materials

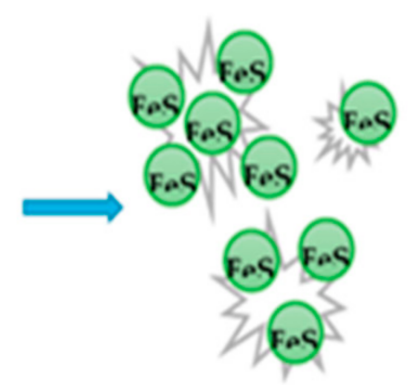

FeS/Supported materials

Figure 5. The modified methods of nano-sized FeS particles: (A) modification by coating stabilizers and (B) modification by physicochemical loading. Adapted and modified from Chen et al. [106], Copyright 2019, Elsevier.

The solution parameters and conditions determine metal adsorption on FeS. The surface charge of the composite and the species distribution of the pollutants, for example, are influenced by $\mathrm{pH}$, as are the rate and capacity of most FeS adsorption [107]. The exact dependence on $\mathrm{pH}$ is contingent on the nature of the adsorbent and adsorbate and the parameters and conditions in which adsorption occurs. This phenomenon can be demonstrated by considering the zero point of charge (ZPC), the $\mathrm{pH}$ at which the total charge on the adsorbent is zero. Chemical species in FeS NCs are significant in determining the total charge on the adsorbents' surfaces. In aqueous media, this $\mathrm{pH}$ is unique to the cations to which the surface oxygen atoms are bound [108]. The opposite charges on $\mathrm{pH}$ at different sides of the ZPC become more pronounced farther away from the ZPC, impacting the recovery process. For example, $\mathrm{Cr}$ (VI) adsorption efficiency on $\mathrm{FeS}$ is high at $\mathrm{pH}$ below the ZPC due to the electrostatic attraction of the dominant-negative $\mathrm{Cr}$ (VI) oxyanions in the solution to the positive surface of the FeS. However, the removal is reduced at higher $\mathrm{pH}$ due to Coulombic repulsion between the anions and the negative FeS surface [62,87].

The specific surface area of adsorption of FeS NPs is greater than those of many other NPs. It is crucial for divalent HM removal from water [109] and offers more active sites in bulk particles [106]. FeS adsorption of divalent HMs may occur by chemical precipitation [105], surface complexation [110,111], and ion exchange [110]. These three processes may occur concurrently [112]. Divalent HMs can also be adsorbed on FeS by chemical coprecipitation and subsequent oxidation reactions [113]. The high HM adsorption is due to HM-S's formation from the dissolution of $\mathrm{S}_{2}{ }^{2-}$ from FeS, caused by the loss of electrons from the Fe. 
Table 2. Support materials, adsorption characteristics, and parameters of some MS NCs.

\begin{tabular}{|c|c|c|c|c|c|c|c|c|c|}
\hline Support & Effect of Support & HM [I0 (mg/L)] & Ads.Dose (g/L) & $\%$ Rem. & Max. Ads. Cap. (mg/g) & $\operatorname{SSA}\left(\mathrm{m}^{2} / \mathrm{g}\right)$ & $\begin{array}{l}\text { Adsorption } \\
\text { Mechanism }\end{array}$ & $\mathrm{pH}$ & Reference \\
\hline ZVI and PS & Increase recovery rate & $\mathrm{Cr}^{6+}(35)$ & 0.50 & 97.0 & 67.9 & 19.5 & $\begin{array}{l}\text { Electrostatic attraction } \\
\text { and redox reaction }\end{array}$ & $3-9$ & [62] \\
\hline $\mathrm{CMC}$ & Stabilizes FeS & $\mathrm{Cd}^{2+}(1)$ & 0.10 & 93.0 & $497.5 \mathrm{mg} / \mathrm{L}^{\mathrm{b}}$ & 44.5 & $\begin{array}{c}\text { Precipitation and } \\
\text { surface complexation }\end{array}$ & 7.0 & [92] \\
\hline Date seed extract & $\begin{array}{l}\text { Reduces iron sulfate } \\
\text { and stabilize FeS }\end{array}$ & $\mathrm{Cr}^{6+}(4.5)$ & 0.5 & 97.0 & 8.50 & 51.0 & $\begin{array}{l}\text { Redox reaction and } \\
\text { precipitation }\end{array}$ & 7.0 & [80] \\
\hline Biochar & $\begin{array}{l}\text { Provides functional } \\
\text { groups }\end{array}$ & $\mathrm{Cr}^{6+}(20)$ & 0.80 & 93.0 & 23.25 & 17.6 & $\begin{array}{l}\text { Electrostatic attraction } \\
\text { and redox reaction }\end{array}$ & 5.2 & [87] \\
\hline $\mathrm{CMC}$ & Stabilizes FeS & $\mathrm{Pb}^{2+}(5.0)$ & 0.05 & 98.0 & 77.0 & - & $\begin{array}{l}\text { Surface complexation } \\
\text { and precipitation }\end{array}$ & 7.0 & [101] \\
\hline ZVI & Activates $\mathrm{FeS}$ & $\mathrm{Sb}^{5+}(100)$ & 0.5 & $\geq 99.18$ & 214.0 & 1.65 & Chemisorption & $2.6-10.6$ & [33] \\
\hline ZVI & Activates FeS & $\begin{array}{c}\mathrm{As}^{3+} \\
\mathrm{As}^{5+}(100)\end{array}$ & 2.0 & $94.5(89.3)$ & $\begin{array}{c}101^{\mathrm{c}} \\
58.3 \mathrm{~L} / \mathrm{mg}\end{array}$ & - & Surface complexation & $3-10$ & [35] \\
\hline Chitosan & $\begin{array}{l}\text { Stabilizes FeS and } \\
\text { provides functional } \\
\text { groups }\end{array}$ & $\mathrm{Cr}^{6+} / \mathrm{Cr}^{3+}(50)$ & 2.0 & 90 (total Cr) & 119 & 14.1 & $\begin{array}{l}\text { Redox reaction, } \\
\text { surface complexation } \\
\text { and precipitation }\end{array}$ & 3.0 & [91] \\
\hline $\mathrm{NaBH}_{4}$ & $\begin{array}{l}\text { Limits FeS oxidation } \\
\text { in air }\end{array}$ & $\begin{array}{c}\mathrm{Cr}^{6+}(50) \\
\mathrm{As}^{5+}(100)\end{array}$ & $\begin{array}{l}0.1 \\
1.0\end{array}$ & $\begin{array}{l}70 \\
56\end{array}$ & $\begin{array}{c}350 \\
28\end{array}$ & - & $\begin{array}{l}\text { Redox reaction and } \\
\text { precipitation } \\
\text { Surface complexation }\end{array}$ & 7.0 & [34] \\
\hline $\mathrm{rGO}$ & Stabilizes $\mathrm{Fe}_{3} \mathrm{~S}_{4}$ & $\mathrm{~Pb}^{2+}$ & 0.75 & 99.5 & 285.7 & 80.96 & $\begin{array}{l}\text { Precipitation and } \\
\text { surface adsorption }\end{array}$ & $3-6$ & [94] \\
\hline
\end{tabular}

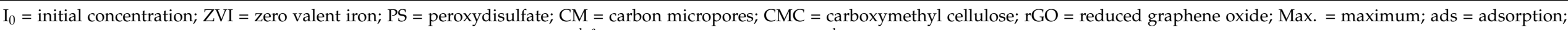
cap. $=$ capacity; SSA $=$ specific surface area; ${ }^{a}$ equilibrium sorption capacity; ${ }^{\mathrm{b} \& \mathrm{c}}$ Langmuir sorption capacity; ${ }^{\mathrm{d}}$ calculated from Freundlich isotherm model. 
The above results are according to the nature of the intermolecular adsorbate-adsorbent bonds. Both chemical and physical adsorptions ensue during the removal of HMs from an aqueous solution by FeS. In other words, adsorption at the solid-liquid interface follows several mechanisms: ion exchange, electrostatic attraction, hydrophobic bonding, hydrogen bond, surface adsorption, and Van der Waals force [114]. Chen et al. [106] summarized the adsorption mechanisms of FeS NPs or NCs as generally occurring in the form of (1) surface adsorption or complexation due to interactions between the FeS and the pollutants and (2) chemical reactions such as precipitation or ion exchange, especially for the divalent HMs. For example, the adsorption kinetics of FeS NMs for divalent $\mathrm{Pb}^{2+}$ is fast due to soft-soft interactions, leading to $\mathrm{Pb}-\mathrm{S}$ bonds' easy formation and surface adsorption [94]. However, surface complexation between the $\mathrm{FeS}$ and $\mathrm{Pb}$ (II) also ensues at the surface of FeS NCs [100]. Cr (VI) adsorption is usually achieved due to surface adsorption [62,91] and redox reaction in which $\mathrm{Cr}$ (VI) is reduced to $\mathrm{Cr}$ (III), and Fe (II) is oxidized to Fe (III), forming mixed iron-chromium oxides/hydroxides [34,62,82,91].

\subsection{Zinc Sulfide}

The scope of ZnS NMs has widened in recent years, with various toxins recovered from aqueous media using ZnS and its NCs. The adsorption capacity of ZnS NMs is high, and their kinetics are fast. The adsorption capacity of NMs is determined by a range of factors, including the NM's size [69]. For example, Yan et al. [88] found that a thinner sorbent exhibits a faster reaction rate, which was explained by the fact that the reaction time is roughly proportional to the square of the size. This observation was accentuated by $\mathrm{Xu}$ et al. [69] using $\mathrm{ZnS} \mathrm{NCs}$ in recovering $\mathrm{Cu}^{2+}$ from water. It was observed that the samples of sizes 20-30 nm, 30-40 nm, and 50-65 nm showed zinc-copper exchange rates of about $98.7 \%, 97.0 \%$, and $38.5 \%$ and surface areas of $15.9 \mathrm{~m}^{2} / \mathrm{g}, 13.8 \mathrm{~m}^{2} / \mathrm{g}$, and $9.5 \mathrm{~m}^{2} / \mathrm{g}$, respectively. Larger particle agglomerates reduce surface area and adsorption capacity. On the other hand, the chelation of sulfur and HM ions on the particle surface, rather than the ion exchange effect, is responsible for decreasing capacity with increasing NP size [115]. The finer ZnS NPs generate tremendous surface energy leading to a more significant number of coordination vacancies of sulfur atoms on the surface, resulting in a high adsorption capacity. Table 3 shows the primary mechanism, size, and other information relevant to the adsorption of HMs with ZnS NMs.

Table 3. HM removal characteristics with ZnS NMs.

\begin{tabular}{|c|c|c|c|c|c|}
\hline Adsorbent & Size (nm) & HM & Max. Ads. Cap. and/or Removal Efficiency & Main Ads. Mechanism & Reference \\
\hline $\mathrm{ZnS} /$ alpha- $\mathrm{Al}_{2} \mathrm{O}_{3}$ & $20-25$ & $\begin{array}{l}\mathrm{Hg}^{2+} \\
\mathrm{Cu}^{2+} \\
\mathrm{Pb}^{2+} \\
\mathrm{Cd}^{2+}\end{array}$ & $\begin{array}{l}99.9 \% \\
99.9 \% \\
90.8 \% \\
66.3 \%\end{array}$ & Cation exchange & [15] \\
\hline $\mathrm{ZnDTC} / \mathrm{ZnS}$ & $1-2$ & $\mathrm{Cr}^{6+}$ & $73.2 \mathrm{mg} / \mathrm{g} ; 99.9 \%$ & Cation exchange & [115] \\
\hline $\mathrm{Fe}_{3} \mathrm{O}_{4} @ \mathrm{ZnS}$ & 750 & $\mathrm{~Pb}^{2+}$ & $272 \mathrm{mg} / \mathrm{g} ; 91 \%$ & Chemisorption & {$[85]$} \\
\hline $\mathrm{Cu} / \mathrm{ZnS}$ & 9.0 & $\begin{array}{l}\mathrm{Co}^{2+} \\
\mathrm{Ni}^{2+} \\
\end{array}$ & $\begin{array}{l}57.0 \mathrm{mg} / \mathrm{g} \\
53.1 \mathrm{mg} / \mathrm{g}\end{array}$ & Electrostatic attraction & [116] \\
\hline $\mathrm{ZnO} / \mathrm{ZnS} /$ biochar & $51.6-69.0(\mathrm{ZnO}+\mathrm{ZnS})$ & $\begin{array}{l}\mathrm{Pb}^{2+} \\
\mathrm{Cu}^{2+} \\
\mathrm{Cr}^{6+}\end{array}$ & $\begin{array}{l}135.8 \mathrm{mg} / \mathrm{g} \\
91.2 \mathrm{mg} / \mathrm{g} \\
24.5 \mathrm{mg} / \mathrm{g}\end{array}$ & Surface complexation & [117] \\
\hline ZnS NPs & - & $\mathrm{Cd}^{2+}$ & $401 \mathrm{mg} / \mathrm{g} ;>99 \%$ & Precipitation & [118] \\
\hline Biochar/ZnS & $7-8$ & $\mathrm{~Pb}^{2+}$ & $368 \mathrm{mg} / \mathrm{g}$ & - & {$[88]$} \\
\hline Dioxa-dithio / ZnS & 33 & $\mathrm{~Pb}^{2+}$ & $99.6 \%$ & $\begin{array}{l}\text { Surface complexation } \\
\text { Electrostatic attraction }\end{array}$ & [119] \\
\hline $\mathrm{ZnS} /$ alpha- $\mathrm{Al}_{2} \mathrm{O}_{3}$ & $\begin{array}{l}20-30 \\
30-40 \\
50-65\end{array}$ & $\mathrm{Cu}^{2+}$ & $\begin{array}{c}650 \mathrm{mg} / \mathrm{g} ; 98.7 \% \\
97.0 \% \\
38.5 \% \\
\end{array}$ & Cation exchange & [69] \\
\hline $\mathrm{ZnS} / \mathrm{ODA}$ & $\begin{array}{c}\text { Length: } 5 \\
\text { Diameter: } 1.2\end{array}$ & $\begin{array}{l}\mathrm{Fe}^{2+} \\
\mathrm{Fe}^{3+} \\
\mathrm{Pb}^{2+}\end{array}$ & - & $\begin{array}{l}\text { Cation exchange } \\
\text { Surface complexation } \\
\text { Precipitation }\end{array}$ & [120] \\
\hline
\end{tabular}

Max. = maximum; ads. = adsorption; cap. = capacity ODA = oxydiacetate . 
The mechanism of HM removal from water with ZnS NCs is generally described as a cationic exchange between the metallic pollutant and the zinc in the adsorbent (Table 3). Cation exchange in water treatment involves removing one or more undesirable cationic contaminants by exchange with another non-objectionable or less objectionable cationic substance. The cation exchange is contingent on the size and charge of the pollutant cations, a fixed ionic charge on a supporting material, the permeability of the material to a solution, the structure of the entire composite, and the stability of the resulting product after adsorption. Divalent HMs exhibited cation exchange on $\mathrm{ZnS}$ NCs with the metal with the more stable sulfide separating first [15]. For $\mathrm{Cu}^{2+}$, the process can be attributed to its similar size and charge as zinc. In contrast, $\mathrm{Hg}^{2+}, \mathrm{Pb}^{2+}$, and $\mathrm{Cd}^{2+}$ ions are a little larger than $\mathrm{Zn}^{2+}$; therefore, the exchange may be due to the $\mathrm{ZnS}$ structure's stability and flexibility that allow these ions in the crystal lattice without disintegrating. However, cation-exchange seems to be a more effective mechanism for $\mathrm{ZnS}$ adsorbents when there is reasonable charge and radii compatibility between $\mathrm{Zn}^{2+}$ and the HM and when NPs of $\mathrm{Zn}_{1-\mathrm{x}} \mathrm{M}_{\mathrm{x}} \mathrm{S}$ (M is a divalent $\mathrm{HM}$ ) develop after adsorption rather than when the pollutant MS is formed $[15,69,120]$.

However, the removal of HMs by ZnS NCs cannot always be explained by cation exchange. Li et al. [117] observed that surface complexation with HMs via hydroxyl ions formation could be responsible for the adsorption of several HMs on $\mathrm{ZnS}$ as it is in line with the Freundlich model for heterogeneous adsorbents [117,120]. Further, HMs having mismatch charges or sizes as zinc are usually adsorbed on ZnS NCs via means other than cation exchange (Table 3). For instance, Malakar et al. [115] observed that although cation exchange could explain the removal of $\mathrm{Fe}^{2+}$ by wurtzite $\mathrm{ZnS}$ nanorods in aqueous solution, $\mathrm{Fe}^{3+}$ favors attachment to the $\mathrm{S}^{2-}$ and surface complexation forming $\beta$-FeOOH oxyhydroxide phases as cation exchange would be energetically unstable due to charge mismatch. Mismatch of sizes between $\mathrm{Zn}^{2+}\left(0.785 \mathrm{~A}^{\circ}\right)$ and $\mathrm{Pb}^{2+}\left(1.33 \mathrm{~A}^{\circ}\right)$ hinders effective ion exchange, rendering removal of $\mathrm{Pb}^{2+}$ pollutant from water in the form of $\mathrm{PbS}$ precipitation. Electrostatic attraction can also account for the removal of HMs from water by $\mathrm{ZnS}$. It was reported that nano-sized $\mathrm{ZnS}$ functionalized with dioxadithio ligands exhibited a negative surface charge at $\mathrm{pH}$ 6, where adsorption of $\mathrm{Pb}^{2+}$ was maximum [119]. This phenomenon can be explained by assuming electrostatic attraction between the $\mathrm{Pb}^{2+}$ ions and the adsorbent's negatively charged surface.

ZnS NCs often have a higher adsorption capacity and are more stable than similar FeS NCs. Wang et al. [118] investigated $\mathrm{Cd}^{2+}$ adsorption with FeS and ZnS, observing that FeS and $\mathrm{ZnS}$ had adsorption capacities of 116 and $401 \mathrm{mg} / \mathrm{g}$ for $\mathrm{Cd}^{2+}$, respectively. While $\mathrm{ZnS}$ takes longer to reach equilibrium, it has a more effective and stable removal effect. The higher capacity of zinc sulfide may be partly because of the ease with which zinc $\left(\mathrm{E}^{0}=\right.$ -0.763) can undergo cation exchange and other interactions with HMs via electrons transfer due to it being a more reactive metal than iron $\left(E^{0}=-0.440\right)$. For practical applications in engineered remediation, a low re-release rate of contaminants and high chemical stability are required [118]. With $\mathrm{ZnS}$, no significant amount of captured $\mathrm{Cd}^{2+}$ was released after shaking with ultra-pure water for $24 \mathrm{~h}$ the and aged $\mathrm{ZnS}$ could still achieve $>80 \%$ removal efficiency of $\mathrm{Cd}^{2+}$, significantly greater than those achieved by FeS.

\subsection{Molybdenum Sulfides}

Two-dimensional layered $\mathrm{MoS}_{2}$ is an archetypical transition metal dichalcogenide (TMD) material rich in sulfur and has become one of the most popular NMs due to its outstanding optical, electronic, and environmental remediation properties. The adsorption mechanism of HMs on most $\mathrm{MoS}_{2} \mathrm{NMs}$ follows the pseudo-first-order kinetics and the Langmuir isotherm indicating single-layer adsorption/chemisorption. However, the specific adsorption mechanism and high capacity of $\mathrm{MoS}_{2}$ for HMs are generally attributed to ion exchange, complexation, and electrostatic interaction with the formation of HM-S complex due to the abundant sorption sites on the surface of $\mathrm{MoS}_{2}$ (Table 4). Since $\mathrm{MoS}_{2}$ NSs typically have a negative surface charge with $\mathrm{H}^{+}$or $\mathrm{Li}^{+}$as a counterion, the first 
possible adsorption process is ion exchange, which leads to metal-sulfur bonding [121,122]. The second primary mechanism is considered to be complexation. $\mathrm{Hg}^{2+}$ ions can replace $\mathrm{H}^{+}$ions to form complexes with one or two sulfur atoms at high or low $\mathrm{Hg}$-to-MoS $\mathrm{Mr}_{2}$ ratios. Another potential mechanism is the electrostatic attraction in the outer layer [123]. It is not infrequent for more than one of these adsorption processes to occur concurrently with the same $\mathrm{MoS}_{2}$ NC [124]. An analysis of the adsorption mechanism showed that the increased $\mathrm{Pb}$ (II) removal on the surface of $\mathrm{MoS}_{2}$ is due to electrostatic interaction, surface diffusion, and the formation of $\mathrm{PbMoO}_{4}$ on the surface of the adsorbent [125]. The complexation of $\mathrm{S}$ with HMs is a key adsorption mechanism of MSs and is controlled by the HM's concentration. For instance, when deficient, $\mathrm{Hg}^{2+}$ forms complexes with two $\mathrm{S}$ atoms but combines with a single $\mathrm{S}$ atom in abundance relative to $\mathrm{MoS}_{2}$ [9].

Table 4. HM adsorption characteristics on $\mathrm{MoS}_{2} \mathrm{NMs}$.

\begin{tabular}{|c|c|c|c|c|c|c|c|}
\hline Adsorbent & HM & $\mathrm{pH}$ & Co-Existing Ions/Effect & \% Rem. & $\begin{array}{l}\text { Specific Ads. } \\
\text { Mechanism }\end{array}$ & $\begin{array}{c}\text { Kinetic } \\
\text { Model/Isotherm }\end{array}$ & Ref \\
\hline 2D amorphous $\mathrm{MoS}_{3}$ & $\begin{array}{l}\mathrm{Cu}^{2+} \\
\mathrm{Cd}^{2+} \\
\mathrm{Hg}^{2+}\end{array}$ & 6.0 & $\begin{array}{l}\mathrm{Al}_{3}{ }^{+}, \mathrm{Fe}^{2+} \mathrm{Mg}^{2+}, \mathrm{Ca}^{2+} \\
(\% \text { rem. of } \mathrm{HM} \text { still }>90 \\
\text { after } 4 \text { cycles })\end{array}$ & $>99.5$ & $\begin{array}{l}\text { Single-layer } \\
\text { adsorption }\end{array}$ & PSO/Langmuir & [25] \\
\hline $\mathrm{C} @ \mathrm{MoS}_{2} / \mathrm{MMT}$ & $\mathrm{Pb}^{2+}$ & 6.0 & $\begin{array}{c}\mathrm{Cu}^{2+}, \mathrm{Cd}^{2+}, \mathrm{Zn}^{2+}, \mathrm{Cr}^{6+} \\
(\mathrm{CI} \text { have little effect })\end{array}$ & $>95.0$ & $\begin{array}{l}\text { Electrostatic } \\
\text { interaction, surface } \\
\text { diffusion and } \\
\text { formation of } \\
\text { PbMoO4. }\end{array}$ & PSO/Langmuir & [125] \\
\hline $\mathrm{MoS}_{2} / \mathrm{CTAB}$ & $\begin{array}{l}\mathrm{Cr}^{6+} \\
\mathrm{Ni}^{2+}\end{array}$ & 7.0 & $\begin{array}{c}\mathrm{SiO}_{3}{ }^{2-}, \mathrm{SO}_{4}{ }^{2-}, \mathrm{CO}_{3}^{2-}, \\
\mathrm{Mg}^{2+}, \mathrm{Ca}^{2+}, \mathrm{Na}^{2+}\left(\mathrm{CI}^{2} \text { have }\right. \\
\text { no effects on } \mathrm{Cr}^{6+} \\
\text { adsorption but affected } \\
\text { the } \mathrm{Ni}^{2+} \text { removal } \\
\text { significantly) }\end{array}$ & $>99.9$ & $\begin{array}{c}\text { Redox reaction; } \\
\text { Electrostatic } \\
\text { attraction and outer } \\
\text { surface complexation }\end{array}$ & PSO/Langmuir & [126] \\
\hline P-PVDF/ $\mathrm{MoS}_{2}$ & $\mathrm{Hg}^{2+}$ & $4.5-6.0$ & $\begin{array}{c}\mathrm{Pb}^{2}, \mathrm{Cu}^{2+}, \mathrm{Cd}^{2+}, \mathrm{Hg}^{2+}, \\
\mathrm{SO}_{4}{ }^{2-} \mathrm{CH}_{3} \mathrm{COO}^{-}, \\
\mathrm{H}_{2} \mathrm{PO}_{4}{ }^{-}, \mathrm{Cl}^{-}, \mathrm{NO}_{3}{ }^{-} \\
\text {(little effect: }<3 \% \text { fall in } \\
\text { rem. rate) }\end{array}$ & $>95.0$ & $\begin{array}{l}\text { Chelation and } \\
\text { precipitation }\end{array}$ & PSO/Langmuir & [127] \\
\hline $1 \mathrm{~T}-\mathrm{MoS}_{2}$ & $\mathrm{Cr}^{6+}$ & 6.0 & $\begin{array}{l}\mathrm{Na}^{+}, \mathrm{K}^{+}, \mathrm{Cu}^{2+}, \mathrm{Mg}^{2+}, \mathrm{Ca}^{2+}, \\
\mathrm{SO}_{4}{ }^{2-} \mathrm{CO}_{3}{ }^{2-}, \mathrm{Cl}^{-}, \mathrm{NO}_{3}{ }^{-}, \\
\mathrm{PO}_{4}{ }^{3-}, \mathrm{AsO}_{3}{ }^{-} \text {(no effect) }\end{array}$ & $>99.9$ & Redox rxn & PSO/Langmuir & [18] \\
\hline Ultrathin $\mathrm{MoS}_{2}$ & $\begin{array}{l}\mathrm{Cd}^{2+} \\
\mathrm{Cu}^{2+} \\
\mathrm{Ag}^{+}\end{array}$ & 6.0 & - & $\begin{array}{c}185.2^{\mathrm{a}} \\
169.5 \\
70.4\end{array}$ & $\begin{array}{c}\text { Physical hole-filling } \\
\text { effects and } \\
\text { electrostatic } \\
\text { interactions }\end{array}$ & PSO/Langmuir & [128] \\
\hline $\mathrm{MoS}_{2} / \mathrm{Fe}_{3} \mathrm{O}_{4}$ & $\mathrm{Hg}^{2+}$ & 5.0 & $\begin{array}{c}\mathrm{Cu}^{2+}, \mathrm{Cd}^{2+}, \mathrm{Zn}^{2+}, \mathrm{Mg}^{2+} \\
\text { (little effect only on } \mathrm{Pb}^{2+} \text { ) }\end{array}$ & $>99.9$ & $\begin{array}{l}\text { Soft-soft interaction } \\
\text { cation exchange and } \\
\text { electrostatic } \\
\text { interaction }\end{array}$ & PSO/Langmuir & [124] \\
\hline $\mathrm{A} 500-\mathrm{MoS}_{4}$ & $\begin{array}{l}\mathrm{Pb}^{2+} \\
\mathrm{Hg}^{2+}\end{array}$ & 5.0 & $\begin{array}{c}\mathrm{Na}^{+}, \mathrm{Cu}^{2+}, \mathrm{Mg}^{2+}, \mathrm{Ca}^{2+}(\mathrm{CI} \\
\text { have no effect at } \mathrm{pH}<1)\end{array}$ & $>99.5$ & Soft-soft interaction & PSO/Langmuir & [129] \\
\hline $\mathrm{MoS}_{2} \mathrm{NSs}$ & $\begin{array}{c}\mathrm{U}^{6+} \\
\mathrm{Th}^{4+}\end{array}$ & $\begin{array}{c}>7.5 \\
6.0\end{array}$ & $\begin{array}{c}\mathrm{Na}^{+}, \mathrm{K}^{+}, \mathrm{Mg}^{2+}, \mathrm{ClO}_{4}^{-}, \\
\mathrm{Cl}^{-}, \mathrm{NO}_{3}^{-}(\text {Effects of } \mathrm{CI} \\
\text { are significantly higher on } \\
\left.\mathrm{U}^{6+} \text { than on } \mathrm{Th}^{4+}\right)\end{array}$ & $\begin{array}{c}492.72^{b} \\
454.72\end{array}$ & $\begin{array}{l}\text { Electrostatic } \\
\text { interaction/inner- } \\
\text { sphere surface } \\
\text { complexation }\end{array}$ & PSO/Freundlich & [130] \\
\hline D-MoS 2 & $\mathrm{Cr}^{6+}$ & 6.0 & $\begin{array}{c}\mathrm{SO}_{4}{ }^{2-}, \mathrm{Cl}^{-}, \mathrm{NO}_{3}{ }^{-}, \\
\mathrm{H}_{2} \mathrm{PO}_{4}{ }^{-}, \mathrm{Na}^{+}, \mathrm{Cu}^{2+}, \mathrm{Mg}^{2+}, \\
\mathrm{Ca}^{2+}, \mathrm{Ni}^{2+}(\mathrm{No} e f f e c t s \\
\text { except for highly } \\
\text { concentrated } \mathrm{Cu}^{2+} \text { which } \\
\text { lowers } \mathrm{Cr}^{6+} \text { rem.) }\end{array}$ & $>99.9$ & $\begin{array}{l}\text { Electrostatic } \\
\text { interaction and } \\
\text { redox rxn }\end{array}$ & PSO/Langmuir & [131] \\
\hline
\end{tabular}

Rem = remain; $\mathrm{CI}$ = co-existing ion; $\mathrm{CTAB}$ = cetyl trimethyl ammonium bromide; PSO = pseudo second-order; $\mathrm{P}$-PVDF = polyvinylidene fluoride polymer matrix; $\mathrm{CMoS}_{2} / \mathrm{MMT}=$ carbonized glucose $\mathrm{MoS}_{2} /$ montmorillonite; D-A500- $\mathrm{MoS}_{2}=$ anion resin based amorphous molybdenum sulfide composite; $\mathrm{MoS}_{2}=$ defect-rich $\mathrm{MoS}_{2} ; \mathrm{rxn}=$ reaction; $\mathrm{NS}=$ nanosheet; ${ }^{\text {\& } \mathrm{b}}$ Adsorption capacity in mg/g.

Both inner and outer surface complexation have been reported with HM removal on $\mathrm{MoS}_{2} \mathrm{NCs}$ and can be indicated by how strongly the sorption is influenced by $\mathrm{pH}$ and ionic strength. When the sorption is strongly affected by $\mathrm{pH}$ but not by the ionic strength, the sorption mechanism is predominantly inner-sphere surface complexation; 
conversely, outer-sphere surface complexation or ion exchange preponderates with the opposite case [132,133].

Li et al. [130] reported that ionic strength had little effect on sorption, implying that inner-sphere surface complexation dominated the sorption processes for the adsorption of $\mathrm{U}(\mathrm{VI})$ and Th (IV) on the surface of $\mathrm{MoS}_{2}$. On the other hand, outer-sphere complexation may be more responsive to ionic strength fluctuations since the background electrolyte ions are placed in the same plane for outer-sphere complexes [58]. Ionic strength affects the double layer's thickness and the interface potential, influencing the binding of the adsorbed species [134]. Others reported the outer-sphere surface process as the dominant adsorption mechanism for removing HMs from aqueous media using $\mathrm{MoS}_{2}[60,126]$. Besides, complexation occurs with the replacement of $\mathrm{S}$ atoms by the surface $\mathrm{O}$ atoms, which can serve as surface binding sites for HMs [135]. The oxygen-containing groups on the surface of $\mathrm{MoS}_{2}$ increase with a rise in $\mathrm{pH}$ [130]. The increased removal efficiency can be attributed to the robust complexation between the HMs and the oxygen atom [136].

While inner layer chemical complexation may substantially reduce the negative surface charge of $\mathrm{MoS}_{2}$ and render electrostatic attraction a minor adsorption mechanism $[121,137]$, the latter interaction can still play a significant role in the adsorption of HMs, especially with those that are unable of complexing with $\mathrm{MoS}_{2}$ [123]. Even with HMs capable of forming complexes with $\mathrm{MoS}_{2}$, electrostatic attraction can explain the experimental adsorption capacities that are higher than the theoretical values. Jia et al. [121] confirmed multilayer adsorption of $\mathrm{Hg}^{2+}$ from aqueous solution using $\mathrm{MoS}_{2}$ besides the inner layer complexation that occurred, indicating an attraction of the positive ions to the negative surface of the adsorbent. The specific surface area of sorbents and the interaction between adsorbents and adsorbates affect the sorption capacity, while the rate of water-soluble ions and the degree of electrostatic interaction may be contingent on the strength/value of the surface charge of the sorbent [128]. Increasing the quantity of $\mathrm{MoS}_{2}$ in the $\mathrm{MoS}_{2}$ NC increases the adsorbent's negative surface charge and the adsorption capacity [138]. However, the surface area of $\mathrm{MoS}_{2} \mathrm{NC}$ decreased as the wt.\% of $\mathrm{MoS}_{2}$ increased, indicating that the predominant adsorption mechanism was electrostatic interaction.

Additionally, the electrostatic interaction is generally $\mathrm{pH}$-dependent and governed by ionic strength. Due to the elevated negative charges on $\mathrm{MoS}_{2}$, there is a more significant electrostatic interaction between $\mathrm{MoS}_{2}$ and HMs at higher $\mathrm{pH}$, resulting in a rise of HM adsorption. Electrostatic interactions may be responsible for the $\mathrm{pH}$-dependent $\mathrm{Cr}$ (VI) on $\mathrm{MoS}_{2}$ and are the results of protonation and deprotonation of the sorbent surface [126]. This observation is partly validated by the robust effect of ionic strength on the adsorption. The beneficial effects of high ionic strength may be attributed to more efficient shielding of heavily charged surface complexes. A critical $\mathrm{Cr}(\mathrm{VI})-\mathrm{Cr}(\mathrm{VI})$ intermolecular electrostatic repulsion force exists. However, improved charge shielding at high ionic strength will reduce electrostatic repulsion, resulting in increased $\mathrm{Cr}(\mathrm{VI})$ recovery [126]. The adsorption capacity may also be affected by the HM ions' charge values related to the strength of the electrostatic activity between the adsorbate and the adsorbent. With $\mathrm{MoS}_{2}$ NS, the adsorption capacity of $\mathrm{Ag}^{+}$was much lower than those of $\mathrm{Cu}^{2+}$ and $\mathrm{Cd}^{2+}$ [128].

$\mathrm{MoS}_{2}$ has a significant number of available adsorption sites due to its peculiar 2D structure and excess of exposed sulfur atoms and hence has an excellent HM ion removal capacity in water $[9,121,123,126,128,130,137,139]$. The same sorbent material having different synthetic techniques exhibits different sorption performance for the same adsorbate since the sorbent will have different characteristics such as structures, morphologies, adsorption sites, and thicknesses. However, efficient removal of pollutants from water by adsorption requires optimization of parameters and conditions governing the adsorption process. For example, while rising $\mathrm{pH}$ amplifies the negative charges on the surface of $\mathrm{MoS}_{2}$, a strongly alkaline solution would engender the formation of HM-OH complexes [140,141], reducing the adsorption efficiency of the sorbent. As a result, $\mathrm{HM}$ ion adsorption's optimum $\mathrm{pH}$ on $\mathrm{MoS}_{2}$ is found in the range of 4.5-7.5 (Table 4) [126-128,130,139]. Interestingly, the highest limit of around $\mathrm{pH} 8$ may be general for MS-NMs because of the same reason. 
Another critical parameter, the time required for arriving at equilibrium (equilibrium contact time), depends on the adsorbent's nature and the adsorbate's concentration. With increasing contact time, the initial rapid increase in removal efficiency of $\mathrm{HMs}$ on $\mathrm{MoS}_{2}$ NCs $[84,121,122,124,128,130]$ can be attributed to abundant vacant adsorbent sites and high solute concentration gradient before equilibrium. The flattening shape of the removal efficiency curve with time could indicate reduced active sites just before equilibrium and a possible HM monolayer deposition on the outer surface with HM diffusion through this coating into the internal cavity of $\mathrm{MoS}_{2}$ particles. The suggestion of chemisorption being the controlling mechanism is validated by the pseudo-second-order kinetic model's better agreement with most of the studies' experimental data (Table 4).

One of the most crucial process parameters under actual conditions at a watertreatment plant is the adsorbent selectivity. Co-existing ions in the water limit adsorption capacity for HMs removal significantly on adsorbents' active sites. The adverse effect is caused by the competition between the HMs and other ions in the water for the active adsorption sites at the increased ionic strength [142]. Interestingly, $\mathrm{MoS}_{2}$ can efficiently adsorb various cations and anions of HMs depending on the adsorption conditions [124], [126,130,131]. The effects of various anions and cations on the adsorption of HMs on $\mathrm{MoS}_{2}$ are shown in Table 4. However, the robust selectivity of $\mathrm{MoS}_{2}$ towards the HMs and resistance to these foreign ions (strong acids and bases) agrees with the Pearson acid-base concept, i.e., the degree of resistance is proportional to the Pearson hardness of the ions. Chalcophiles exhibit differing affinities for chalcogenides, which may lead to varying adsorption capacities of $\mathrm{MoS}_{2}$ for HMs depending on the metals' degree of softness. For example, $\mathrm{Hg}^{2+}>\mathrm{Pb}^{2+}>\mathrm{Zn}^{2+}>\mathrm{Cu}^{2+}>\mathrm{Cd}^{2+}$ represents the order of removal efficiency of $\mathrm{MoS}_{2} / \mathrm{Fe}_{3} \mathrm{O}_{4}$ nanohybrid [124,143], relatively consistent with the level of metal softness.

\subsection{Copper Sulfides}

Semiconductor chalcogenides, such as copper sulfide (CuS) nanostructures, have recently drawn much interest due to their variety, low cost, and extraordinary electronic and optical properties. However, without a proper surface coating, these nanostructures, like their FeS equivalents, aggregate rapidly in water, reducing efficiency. As a result, a considerable effort has gone into developing appropriate materials for modifying the surface of copper sulfide nanocrystals, with the support or matrix chosen to be crucial. Several investigations have shown that biomolecules are efficient at preventing NM agglomeration [144]. However, CuS NMs demonstrate relatively better air-stability [145] than the $\mathrm{FeS}$, and their oxidation in the air is not as rapid as FeS.

Compared with other transition metal ( $\mathrm{Zn}, \mathrm{Fe}$, and Mo) sulfides, $\mathrm{CuS}$ has been sparingly applied to remove HMs from water in recent years. However, where CuS NMs are employed, they exhibit excellent and unique adsorption characteristics for HMs. For example, Yao et al. [146] synthesized inexpensive CuS NPs, which exhibited highly selective binding and extremely efficient adsorption performance for the noble metals $\left(\mathrm{Au}^{3+}\right.$, $\mathrm{Pd}^{2+}$ and $\mathrm{Pt}^{4+}$ ). Significantly, after adsorption, $\mathrm{CuO} / \mathrm{CuS} \mathrm{NCs}$ can agglomerate with the contaminant and self-deposit, withdrawing from the supernatant without the use of a complex centrifugation system or an external magnetic field, ushering in a water purification milestone [147]. Due to their porous nature and the close interaction between the HM cations and $\mathrm{S}^{2-}$, some CuS NCs have shown comparatively higher adsorption capacities of 3096 and $2787 \mathrm{mg} / \mathrm{g}$ for $\mathrm{Hg}$ (II) and Pb (II), respectively [148]. The adsorption with CuS NMs ensues via a variety of adsorption mechanisms, including ion exchange [144,148], and electrostatic interaction $[146,149]$. Chemical exchange is evidenced by the Langmuir isotherm model, which assumes that monolayer molecules adsorb onto adsorbents' homogeneous active sites or that all adsorption sites have the same affinity for adsorbates. CuS NCs may undergo ion exchange with divalent HMs primarily through the process: $\mathrm{CuS}+\mathrm{M}^{2+} \rightarrow \mathrm{MS}+\mathrm{Cu}^{2+}[150]$. However, the removal efficiency of CuS NCs may drop at $\mathrm{pH}$ below the $\mathrm{ZPC}$ but rise rapidly as the $\mathrm{pH}$ increases, indicating a possible electrostatic attraction [149]. 


\subsection{Other MS-NMs}

The structural properties of titanium (IV) sulfide (TiS2) determine its electronic and chemical activity. $\mathrm{TiS}_{2}$ NPs may have higher binding capacities than other binary titanium compounds due to their layered structure, allowing ion intercalation between layers and electrochemical action. Cantu et al. [151] prepared $\mathrm{TiS}_{2}$ NPs with a complex morphology made up of arrays of $\mathrm{TiS}_{2}$ platelets that gave them a flower-like appearance with a thin edge plane at the end of a larger basal plane. These NMs adsorbed $\mathrm{Cu}^{2+}$ and $\mathrm{Pb}^{2+}$ more efficiently at lower $\mathrm{pH}$ than at higher $\mathrm{pH}$, contrasting with the high physisorption (electrostatic attraction) observed with other adsorbents as $\mathrm{pH}$ rises $[74,94,119]$. The adsorption implies that the interaction between the divalent ions and $\mathrm{TiS}_{2}$ is the formation of a chemical bond rather than just physical sorption.

The pyrite-type material cobalt disulfide $\left(\mathrm{CoS}_{2}\right)$ is extensively used in catalysis, supercapacitors, and energy storage $[19,152]$. $\mathrm{CoS}_{2}$-based adsorbents are developed with a support that prevents agglomeration, an inherent disadvantage of many MS adsorbents $[55,82,87]$. $\mathrm{Hg}^{2+}$ removal on $\mathrm{CoS}_{2} \mathrm{NCs}$ is weak at low $\mathrm{pH}$ [due to repulsion between the protonated surface and $\mathrm{Hg}$ (II) ions]. The removal at this point was due to surface complexation between the $\mathrm{Hg}^{2+}$ and $\mathrm{S}^{2-}$ species. With a rise in $\mathrm{pH}$, the removal efficiency and adsorption capacity increase, indicating that adsorption occurs by electrostatic action. The Langmuir isotherm model with the highest $R^{2}$ implied monolayer adsorption, and the pseudo-second-order kinetic model best fit the experimental data, indicating that chemosorption is the rate-determining process [144,153].

Inexpensive two-dimensional cadmium sulfide (CdS) NPs exhibit an enormous capacity to remove HMs with excellent physicochemical characteristics, including an enhanced exposure and high specific surface area, porous structure abundant in surface-active sites, and high chemical stability $[154,155]$. CdS NPs removal of $\mathrm{Hg}^{2+}$ from aqueous media is very rapid and completed in few minutes due to vacant active sites at the beginning $[36,156]$. The adsorption behavior is consistent with the Langmuir-type adsorption isotherm model and pseudo-second-order kinetic model. Similarly, with other MSs, the HM's adsorption on these CdS NCs may be $\mathrm{pH}$-dependent, increasing with $\mathrm{pH}$ up to between $\mathrm{pH}$ 5-7 and falling again $[36,149,156]$ due to precipitation of metal hydroxides.

\subsection{A Note on the Controversy of NM Usage and Long-Term Impact on the Environment}

It is undeniable that nanoparticles provide a plethora of chances and possibilities for improved health and a cleaner environment. However, the safety and long-term consequences of increased NM usage and disposal in the environment are unknown. However, due to the fact that nanoparticles display extremely high reactivity not seen in corresponding bulk particles, there are significant safety concerns that MS-NMs may be harmful to public health $[157,158]$. The robust reactivity and other properties of NMs can be used to remove contaminants from water, but these same qualities may also produce undesirable by-products [158]. According to literature reviews [157,158], NMs have the potential to harm living organisms when exposed over lengthy periods of time. However, the surveys reported that the influence of NMs on health is still a source of debate, with some academics claiming toxicity and others disputing it $[157,158]$. However, as the types and quantities of NMs in the environment rise, it is critical to find a definitive response to the topic of NM environmental toxicity. Formulating and executing research to this purpose can lead to a decisive result.

\section{Conclusions and Prospect}

This article summarizes the most recent developments in using MS-NMs to recover HMs by adsorption from contaminated water. MS-NMs include some of the most promising two-dimensional layered NMs for offsetting environmental damage, especially the sequestration of HMs from aquatic environments. The structure, synthesis, support material, characterization, and heavy metal adsorption mechanism of MS-NMs have been discussed. Recent advances in MS-NM applications have been identified and highlighted. 
Their advantages and disadvantages are also mentioned. MS-NMs are a more potent adsorbent for removing HMs from aqueous media than traditional metal adsorbents. Although significant efforts have been made in MS-NMs studies to remove HMs, many unsolved problems and challenges must be overcome before their commercial applications can be implemented. Steps leading to remedying this situation entail addressing some of the gaps and research challenges.

A major disadvantage of most MS-NMs is the failure to separate from the supernatant rapidly. One primary solution is to combine MS-NMs with expensive magnetic NPs. Hence, there is still a great need for research on scalable MS-NMs production at low cost and easy operation while maintaining and enhancing active sites. Additionally, most studies have evaluated the effectiveness of MS-NMs in removing moderately high or very high HM levels in the laboratory. Hence, studies with environmentally relevant HM concentrations should be carried out. As discussed in the current work, it is not uncommon for the water to be contaminated with multiple metals. It is, therefore, appropriate to investigate the effectiveness of MS-NMs with simultaneous contamination. This review shows that most MS-NMs oxidize when in specific solutions or when exposed to air. Consequently, studies on MS-NMs stability and the development or discovery of appropriate support/stabilizing structures for MS-NMs for efficient removal of HMs from water require more attention. Moreover, there is a lack of adequate knowledge on the regeneration and reusability of MS-NMs, which requires further investigation. Relative to MS-NMs, there is a need to establish nanomaterial adsorbents evaluation protocol and life cycle assessment to test NMs at the material discovery stage, considering both adsorption capacity and mass transfer kinetics and to perform long-term testing in real applications. A comparison between the mechanism of heavy metals detection and the methods' sensitivity and selectivity, on one hand, and the commonly used analytic techniques on the other hand, is warranted.

This review has endeavored to present evidence that this category of materials has enormous potential as $\mathrm{HM}$ adsorbents. It is anticipated that this analysis will provide a comprehensive overview of the most recent studies on the use of MS-NMs in HM removal and a strong motivation to continue developing these NMs for future and sustainable environmental remediation research, especially in the field of HM abatement in water.

Author Contributions: Conceptualization, writing—original draft preparation, writing-review and editing, V.K.; supervision, and funding acquisition, G.Z. All authors have read and agreed to the published version of the manuscript.

Funding: The Major Science and Technology Program for Water Pollution Control and Treatment of China (2015ZX07406006) and Seed Foundation of Tianjin University (2015).

Institutional Review Board Statement: Not applicable.

Informed Consent Statement: Not applicable.

Data Availability Statement: Not applicable.

Acknowledgments: The authors wish to extend profound gratitude to students of the Laboratory of Water Treatment with Membrane, Tianjin University, especially Wenxiu Zhang, Yaoyao Zhong, and Wenqiang Wang, for their encouragement and support.

Conflicts of Interest: The authors declare no conflict of interest.

\section{References}

1. Liu, D.; Li, B.; Wu, J.; Liu, Y. Elemental mercury capture from industrial gas emissions using sulfides and selenides: A review. Environ. Chem. Lett. 2020, 19, 1-17. [CrossRef]

2. Chen, S.; Hu, J.; Han, S.; Guo, Y.; Belzile, N.; Deng, T. A review on emerging composite materials for cesium adsorption and environmental remediation on the latest decade. Sep. Purif. Technol. 2020, 251, 117340. [CrossRef]

3. Liu, Y.; Wang, H.; Yuan, X.; Wu, Y.; Wang, H.; Tan, Y.Z.; Chew, J.W. Roles of sulfur-edge sites, metal-edge sites, terrace sites, and defects in metal sulfides for photocatalysis. Chem. Catal. 2021, 1, 44-68. [CrossRef] 
4. Ha, D.-H.; Caldwell, A.H.; Ward, M.J.; Honrao, S.; Mathew, K.; Hovden, R.; Koker, M.K.A.; Muller, D.A.; Hennig, R.G.; Robinson, R.D. Solid-Solid Phase Transformations Induced through Cation Exchange and Strain in 2D Heterostructured Copper Sulfide Nanocrystals. Nano Lett. 2014, 14, 7090-7099. [CrossRef]

5. Fu, W.; Yang, S.; Yang, H.; Guo, B.; Huang, Z. 2D amorphous MoS 3 nanosheets with porous network structures for scavenging toxic metal ions from synthetic acid mine drainage. J. Mater. Chem. A 2019, 7, 18799-18806. [CrossRef]

6. Hai, X.; Chang, K.; Pang, H.; Li, M.; Li, P.; Liu, H.; Shi, L.; Ye, J. Engineering the edges of MoS2 (WS2) crystals for direct exfoliation into monolayers in polar micromolecular solvents. J. Am. Chem. Soc. 2016, 138, 14962-14969. [CrossRef]

7. Yin, L.; Hai, X.; Chang, K.; Ichihara, F.; Ye, J. Synergetic exfoliation and lateral size engineering of MoS2 for enhanced photocatalytic hydrogen generation. Small 2018, 14, 1704153. [CrossRef]

8. Ma, S.; Huang, L.; Ma, L.; Shim, Y.; Islam, S.M.; Wang, P.; Zhao, L.-D.; Wang, S.; Sun, G.; Yang, X. Efficient uranium capture by polysulfide/layered double hydroxide composites. J. Am. Chem. Soc. 2015, 137, 3670-3677. [CrossRef] [PubMed]

9. Ai, K.; Ruan, C.; Shen, M.; Lu, L. MoS2 nanosheets with widened interlayer spacing for high-efficiency removal of mercury in aquatic systems. Adv. Funct. Mater. 2016, 26, 5542-5549. [CrossRef]

10. Wang, Z.; Mi, B. Environmental applications of 2D molybdenum disulfide (MoS2) nanosheets. Environ. Sci. Technol. 2017, 51, 8229-8244. [CrossRef]

11. Sankararamakrishnan, N.; Singh, R.; Srivastava, I. Performance of novel MgS doped cellulose nanofibres for Cd (II) removal from industrial effluent-mechanism and optimization. Sci. Rep. 2019, 9, 1-8. [CrossRef]

12. Chandrasekaran, S.; Yao, L.; Deng, L.; Bowen, C.; Zhang, Y.; Chen, S.; Lin, Z.; Peng, F.; Zhang, P. Recent advances in metal sulfides: From controlled fabrication to electrocatalytic, photocatalytic and photoelectrochemical water splitting and beyond. Chem. Soc. Rev. 2019, 48, 4178-4280. [CrossRef]

13. Zhao, J.; Zhang, Y.; Wang, Y.; Li, H.; Peng, Y. The application of nanostructured transition metal sulfides as anodes for lithium ion batteries. J. Energy Chem. 2018, 27, 1536-1554. [CrossRef]

14. Sahoo, A.K.; Srivastava, S.K.; Raul, P.K.; Gupta, A.K.; Shrivastava, R. Graphene nanocomposites of CdS and ZnS in effective water purification. J. Nanoparticle Res. 2014, 16, 1-17. [CrossRef]

15. Fang, L.; Li, L.; Qu, Z.; Xu, H.; Xu, J.; Yan, N. A novel method for the sequential removal and separation of multiple heavy metals from wastewater. J. Hazard. Mater. 2018, 342, 617-624. [CrossRef] [PubMed]

16. Gupta, D.; Chauhan, V.; Kumar, R. A comprehensive review on synthesis and applications of molybdenum disulfide (MoS2) material: Past and recent developments. Inorg. Chem. Commun. 2020, 121, 108200. [CrossRef]

17. Lukowski, M.A.; Daniel, A.S.; Meng, F.; Forticaux, A.; Li, L.; Jin, S. Enhanced Hydrogen Evolution Catalysis from Chemically Exfoliated Metallic MoS2 Nanosheets. J. Am. Chem. Soc. 2013, 135, 10274-10277. [CrossRef]

18. Li, Z.; Fan, R.; Hu, Z.; Li, W.; Zhou, H.; Kang, S.; Zhang, Y.; Zhang, H.; Wang, G. Ethanol introduced synthesis of ultrastable 1T-MoS2 for removal of Cr(VI). J. Hazard. Mater. 2020, 394, 122525. [CrossRef]

19. Zhao, X.; Ma, X.; Sun, J.; Li, D.; Yang, X. Enhanced Catalytic Activities of Surfactant-Assisted Exfoliated WS2 Nanodots for Hydrogen Evolution. Acs Nano 2016, 10, 2159-2166. [CrossRef] [PubMed]

20. Zhao, Z.-Y.; Liu, Q.-L. Study of the layer-dependent properties of MoS2 nanosheets with different crystal structures by DFT calculations. Catal. Sci. Technol. 2018, 8, 1867-1879. [CrossRef]

21. Dou, W.; Yang, W.; Zhao, X.; Pan, Q. Hollow cobalt sulfide for highly efficient uranium adsorption from aqueous solutions. Inorg. Chem. Front. 2019, 6, 3230-3236. [CrossRef]

22. Liu, H.; You, Z.; Yang, S.; Liu, C.; Xie, X.; Xiang, K.; Wang, X.; Yan, X. High-efficient adsorption and removal of elemental mercury from smelting flue gas by cobalt sulfide. Environ. Sci. Pollut. Res. 2019, 26, 6735-6744. [CrossRef] [PubMed]

23. Petrašauskienè, N.; Stokienè, R.; Žalenkienè, S.; Janickis, V. Formation of cobalt sulfide layers on polyamide 6 by sorptiondiffusion method using solutions of dodecathionic acid, $\mathrm{H}_{2} \mathrm{~S}_{12} \mathrm{O}_{6}$. Chemija 2015, 26, 5 .

24. Xia, D.; Gong, F.; Pei, X.; Wang, W.; Li, H.; Zeng, W.; Wu, M.; Papavassiliou, D.V. Molybdenum and tungsten disulfides-based nanocomposite films for energy storage and conversion: A review. Chem. Eng. J. 2018, 348, 908-928. [CrossRef]

25. Vattikuti, V.P.; Shim, J.; Byon, C. 1D Bi2S3 nanorod/2D e-WS2 nanosheet heterojunction photocatalyst for enhanced photocatalytic activity. J. Solid State Chem. 2018, 258, 526-535. [CrossRef]

26. Hu, L.; Song, X.-F.; Zhang, S.-L.; Zeng, H.-B.; Zhang, X.-J.; Marks, R.; Shan, D. MoS $_{2}$ nanoparticles coupled to SnS 2 nanosheets: The structural and electronic modulation for synergetic electrocatalytic hydrogen evolution. J. Catal. 2018, 366, 8-15. [CrossRef]

27. Fu, L.; Yan, Z.; Zhao, Q.; Yang, H. Novel 2D nanosheets with potential applications in heavy metal purification: A review. Adv. Mater. Interfaces 2018, 5, 1801094. [CrossRef]

28. Yu, H.; Xiao, P.; Wang, P.; Yu, J. Amorphous molybdenum sulfide as highly efficient electron-cocatalyst for enhanced photocatalytic H2 evolution. Appl. Catal. B Environ. 2016, 193, 217-225. [CrossRef]

29. Shen, X.; Xia, X.; Ye, W.; Du, Y.; Wang, C. Hexagram-like CoS-MoS2 composites with enhanced activity for hydrogen evolution reaction. J. Solid State Electrochem. 2017, 21, 409-417. [CrossRef]

30. Makovicky, E. Crystal Structures of Sulfides and Other Chalcogenides. Rev. Mineral. Geochem. 2006, 61, 7-125. [CrossRef]

31. Xiong, Y.; Su, L.; Yang, H.; Zhang, P.; Ye, F. Fabrication of copper sulfide using a Cu-based metal organic framework for the colorimetric determination and the efficient removal of $\mathrm{Hg} 2+$ in aqueous solutions. New J. Chem. 2015, 39, 9221-9227. [CrossRef]

32. Liu, D.; Zhang, Z.; Wu, J.; Li, C. Copper sulfide microsphere for $\mathrm{Hg} 0$ capture from flue gas at low temperature. Mater. Today Commun. 2020, 25, 101188. [CrossRef] 
33. He, X.; Min, X.; Peng, T.; Ke, Y.; Zhao, F.; Sillanpää, M.; Wang, Y. Enhanced adsorption of antimonate by ball-milled microscale zero valent iron/pyrite composite: Adsorption properties and mechanism insight. Environ. Sci. Pollut. Res. 2020, 27, 16484-16495. [CrossRef]

34. Han, Y.-S.; Lee, C.-M.; Chon, C.-M.; Kwon, J.A.; Park, J.-H.; Shin, Y.-J.; Lim, D.-H. Enhanced oxidation resistance of NaBH4-treated mackinawite (FeS): Application to Cr (VI) and As (III) removal. Chem. Eng. J. 2018, 353, 890-899. [CrossRef]

35. Min, X.; Li, Y.; Ke, Y.; Shi, M.; Chai, L.; Xue, K. Fe-FeS 2 adsorbent prepared with iron powder and pyrite by facile ball milling and its application for arsenic removal. Water Sci. Technol. 2017, 76, 192-200. [CrossRef] [PubMed]

36. Sereshti, H.; Gaikani, H.; Nodeh, H.R. The effective removal of mercury ions ( $\mathrm{Hg} 2+$ ) from water using cadmium sulfide nanoparticles doped in polycaprolactam nanofibers: Kinetic and equilibrium studies. J. Iran. Chem. Soc. 2018, 15, 743-751. [CrossRef]

37. Ahmad, H.; Sharfan, I.I.B.; Khan, R.A.; Alsalme, A. Effective Enrichment and Quantitative Determination of Trace Hg2+ Ions Using CdS-Decorated Cellulose Nanofibrils. Nanomaterials 2020, 10, 2218. [CrossRef]

38. Cho, G.; Park, Y.; Hong, Y.-K.; Ha, D.-H. Ion exchange: An advanced synthetic method for complex nanoparticles. Nano Converg. 2019, 6, 17. [CrossRef]

39. Qiao, Z.; Shen, M.; Xiao, Y.; Zhu, M.; Mignani, S.; Majoral, J.-P.; Shi, X. Organic/inorganic nanohybrids formed using electrospun polymer nanofibers as nanoreactors. Coord. Chem. Rev. 2018, 372, 31-51. [CrossRef]

40. Vaughan, D.J.; Corkhill, C.L. Mineralogy of Sulfides. Elements 2017, 13, 81-87. [CrossRef]

41. Bentley, C.L.; Kang, M.; Maddar, F.M.; Li, F.; Walker, M.; Zhang, J.; Unwin, P.R. Electrochemical maps and movies of the hydrogen evolution reaction on natural crystals of molybdenite (MoS2): Basal vs. edge plane activity. Chem. Sci. 2017, 8 , 6583-6593. [CrossRef]

42. Zhang, T.; Kong, L.-B.; Dai, Y.-H.; Yan, K.; Shi, M.; Liu, M.-C.; Luo, Y.-C.; Kang, L. A Facile Strategy for the Preparation of MoS3 and its Application as a Negative Electrode for Supercapacitors. Chem. Asian J. 2016, 11, 2392-2398. [CrossRef]

43. Ye, H.; Wang, L.; Deng, S.; Zeng, X.; Nie, K.; Duchesne, P.N.; Wang, B.; Liu, S.; Zhou, J.; Zhao, F.; et al. Amorphous MoS3 Infiltrated with Carbon Nanotubes as an Advanced Anode Material of Sodium-Ion Batteries with Large Gravimetric, Areal, and Volumetric Capacities. Adv. Energy Mater. 2017, 7, 1601602. [CrossRef]

44. Liu, C.; Wang, Q.; Jia, F.; Song, S. Adsorption of heavy metals on molybdenum disulfide in water: A critical review. J. Mol. Liq. 2019, 292, 111390. [CrossRef]

45. Yadav, T.P.; Yadav, R.M.; Singh, D.P. Mechanical Milling: A Top Down Approach for the Synthesis of Nanomaterials and Nanocomposites. Nanosci. Nanotechnol. 2012, 2, 22-48. [CrossRef]

46. Gou, J.; Zhuge, J.; Liang, F. Processing of polymer nanocomposites. In Manufacturing Techniques for Polymer Matrix Composites (PMCs); Elsevier: Amsterdam, The Netherlands, 2012; pp. 95-119.

47. Shi, X.; Zhou, W.; Ma, D.; Ma, Q.; Bridges, D.; Ma, Y.; Hu, A. Electrospinning of Nanofibers and Their Applications for Energy Devices. J. Nanomater. 2015, 2015, 1-20. [CrossRef]

48. Khan, F.A. Synthesis of Nanomaterials: Methods \& Technology. In Applications of Nanomaterials in Human Health; Springer: Berlin/Heidelberg, Germany, 2020; pp. 15-21.

49. Koli, S.K.; Hussain, A. Status of Electronic Waste Management in India: A Review. Adv. Treat. Tech. Ind. Wastewater 2019, 238-250. [CrossRef]

50. Qiao, S.Z.; Liu, J.; Lu, G.Q.M. Synthetic chemistry of nanomaterials. In Modern Inorganic Synthetic Chemistry; Elsevier: Amsterdam, The Netherlands, 2011; pp. 479-506.

51. Ottaviano, L.; Palleschi, S.; Perrozzi, F.; D’Olimpio, G.; Priante, F.; Donarelli, M.; Benassi, P.; Nardone, M.; Gonchigsuren, M.; Gombosuren, M.; et al. Mechanical exfoliation and layer number identification of MoS2 revisited. 2D Mater. 2017, 4, 045013. [CrossRef]

52. Yuan, L.; Ge, J.; Peng, X.; Zhang, Q.; Wu, Z.; Jian, Y.; Xiong, X.; Yin, H.; Han, J. A reliable way of mechanical exfoliation of large scale two dimensional materials with high quality. Aip Adv. 2016, 6, 125201. [CrossRef]

53. Sun, J.; Li, X.; Guo, W.; Zhao, M.; Fan, X.; Dong, Y.; Xu, C.; Deng, J.; Fu, Y. Synthesis Methods of Two-Dimensional MoS2: A Brief Review. Crystals 2017, 7, 198. [CrossRef]

54. Xie, S.; Xu, M.; Liang, T.; Huang, G.; Wang, S.; Xue, G.; Meng, N.; Xu, Y.; Chen, H.; Ma, X.; et al. A high-quality round-shaped monolayer MoS2 domain and its transformation. Nanoscale 2016, 8, 219-225. [CrossRef]

55. Backes, C.; Higgins, T.M.; Kelly, A.; Boland, C.; Harvey, A.; Hanlon, D.; Coleman, J.N. Guidelines for Exfoliation, Characterization and Processing of Layered Materials Produced by Liquid Exfoliation. Chem. Mater. 2017, 29, 243-255. [CrossRef]

56. Wang, Q.; Yang, L.; Jia, F.; Li, Y.; Song, S. Removal of Cd (II) from water by using nano-scale molybdenum disulphide sheets as adsorbents. J. Mol. Liq. 2018, 263, 526-533. [CrossRef]

57. Grayfer, E.D.; Kozlova, M.N.; Fedorov, V.E. Colloidal 2D nanosheets of MoS2 and other transition metal dichalcogenides through liquid-phase exfoliation. Adv. Colloid Interface Sci. 2017, 245, 40-61. [CrossRef] [PubMed]

58. Wang, Z.; von dem Bussche, A.; Qiu, Y.; Valentin, T.M.; Gion, K.; Kane, A.B.; Hurt, R.H. Chemical Dissolution Pathways of MoS2 Nanosheets in Biological and Environmental Media. Environ. Sci. Technol. 2016, 50, 7208-7217. [CrossRef]

59. Fu, J.; Zhu, B.; You, W.; Jaroniec, M.; Yu, J. A flexible bio-inspired H2-production photocatalyst. Appl. Catal. B Environ. 2018, 220, 148-160. [CrossRef]

60. Mercante, L.A.; Andre, R.S.; Schneider, R.; Mattoso, L.H.C.; Correa, D.S. Free-standing $\mathrm{SiO}_{2} / \mathrm{TiO}_{2}-\mathrm{MoS}_{2}$ composite nanofibrous membranes as nanoadsorbents for efficient $\mathrm{Pb}$ (II) removal. New J. Chem. 2020, 44, 13030-13035. [CrossRef] 
61. Sadykov, V.A.; Mezentseva, N.V.; Bobrova, L.N.; Smorygo, O.L.; Eremeev, N.F.; Fedorova, Y.E.; Bespalko, Y.N.; Skriabin, P.I.; Krasnov, A.V.; Lukashevich, A.I.; et al. Advanced Materials for Solid Oxide Fuel Cells and Membrane Catalytic Reactors. In Advanced Nanomaterials for Catalysis and Energy; Elsevier: Amsterdam, The Netherlands, 2019; pp. 435-514. [CrossRef]

62. Wang, K.; Liu, X.; Tang, J.; Wang, L.; Sun, H. Ball milled Fe0@FeS hybrids coupled with peroxydisulfate for Cr(VI) and phenol removal: Novel surface reduction and activation mechanisms. Sci. Total Environ. 2020, 739, 139748. [CrossRef]

63. Iqbal, P.; Preece, J.A.; Mendes, P.M. Nanotechnology: The 'Top-Down' and 'Bottom-Up' Approaches. In Supramolecular Chemistry; Gale, P.A., Steed, J.W., Eds.; John Wiley \& Sons Ltd.: Chichester, UK, 2012. [CrossRef]

64. Zhang, J.; Chernomordik, B.D.; Crisp, R.W.; Kroupa, D.M.; Luther, J.M.; Miller, E.M.; Gao, J.; Beard, M.C. Preparation of $\mathrm{Cd} / \mathrm{Pb}$ Chalcogenide Heterostructured Janus Particles via Controllable Cation Exchange. ACS Nano 2015, 9, 7151-7163. [CrossRef] [PubMed]

65. Cheng, X.; Liu, J.; Wan, X.; Wang, H.; Li, Y.; Liu, J.; Rong, H.; Xu, M.; Chen, W.; Zhang, J. Phosphine ligand-mediated kinetics manipulation of aqueous cation exchange: A case study on the synthesis of Au@SnS $\mathrm{x}_{\mathrm{x}}$ core-shell nanocrystals for photoelectrochemical water splitting. Chem. Commun. 2018, 54, 9993-9996. [CrossRef]

66. Fenton, J.L.; Schaak, R.E. Structure-Selective Cation Exchange in the Synthesis of Zincblende MnS and CoS Nanocrystals. Angew. Chem. 2017, 129, 6564-6567. [CrossRef]

67. Ma, F.-X.; Yu, L.; Xu, C.-Y.; Lou, X.W. Self-supported formation of hierarchical $\mathrm{NiCo}_{2} \mathrm{O}_{4}$ tetragonal microtubes with enhanced electrochemical properties. Energy Environ. Sci. 2016, 9, 862-866. [CrossRef]

68. Yu, X.-Y.; Yu, L.; Lou, X.W.D. Metal Sulfide Hollow Nanostructures for Electrochemical Energy Storage. Adv. Energy Mater. 2016, 6, 1501333. [CrossRef]

69. Xu, J.; Qu, Z.; Yan, N.; Zhao, Y.; Xu, X.; Li, L. Size-dependent nanocrystal sorbent for copper removal from water. Chem. Eng. J. 2016, 284, 565-570. [CrossRef]

70. Powell, A.E.; Hodges, J.M.; Schaak, R.E. Preserving Both Anion and Cation Sublattice Features during a Nanocrystal CationExchange Reaction: Synthesis of Metastable Wurtzite-Type CoS and MnS. J. Am. Chem. Soc. 2016, 138, 471-474. [CrossRef]

71. Barman, D.; Ghosh, S.; Paul, S.; Dalal, B.; De, S.K. Cation Exchange-Mediated Synthesis of Library of Plasmomagnetic Nanoheterostructures: Transformation of 2-Dimensional-Shaped $\mathrm{Fe}_{7} \mathrm{~S}_{8}$ Nanoplates to $\mathrm{Cu}-\mathrm{Fe}-\mathrm{S}$-Based Ternary Compound. Chem. Mater. 2018, 30, 5550-5560. [CrossRef]

72. Fan, Z.; Lin, L.-C.; Buijs, W.; Vlugt, T.J.H.; van Huis, M.A. Atomistic understanding of cation exchange in PbS nanocrystals using simulations with pseudoligands. Nat. Commun. 2016, 7, 11503. [CrossRef]

73. Lei, L.; Huang, D.; Zeng, G.; Cheng, M.; Jiang, D.; Zhou, C.; Chen, S.; Wang, W. A fantastic two-dimensional MoS2 material based on the inert basal planes activation: Electronic structure, synthesis strategies, catalytic active sites, catalytic and electronics properties. Coord. Chem. Rev. 2019, 399, 213020. [CrossRef]

74. Wang, Y.; Bao, S.; Liu, Y.; Yu, Y.; Yang, W.; Xu, S.; Li, H. CoS2/GO nanocomposites for highly efficient and ppb level adsorption of $\mathrm{Hg}(\mathrm{II})$ from wastewater. J. Mol. Liq. 2021, 322, 114899. [CrossRef]

75. Lim, Y.R.; Song, W.; Han, J.K.; Lee, Y.B.; Kim, S.J.; Myung, S.; Lee, S.S.; An, K.-S.; Choi, C.-J.; Lim, J. Wafer-Scale, Homogeneous $\mathrm{MoS}_{2}$ Layers on Plastic Substrates for Flexible Visible-Light Photodetectors. Adv. Mater. 2016, 28, 5025-5030. [CrossRef]

76. Fu, Y.; Li, Q.; Liu, J.; Jiao, Y.; Hu, S.; Wang, H.; Xu, S.; Jiang, B. In-situ chemical vapor deposition to fabricate Cuprous oxide/copper sulfide core-shell flowers with boosted and stable wide-spectral region photocatalytic performance. J. Colloid Interface Sci. 2020, 570, 143-152. [CrossRef]

77. Yu, S.H.; Tang, Z.; Shao, Y.; Dai, H.; Wang, H.Y.; Yan, J.; Pan, H.; Chua, D.H.C. In Situ Hybridizing MoS2 Microflowers on VS2 Microflakes in a One Pot CVD Process for Electrolytic Hydrogen Evolution Reaction. ACS Appl. Energy Mater. 2019, 2, 5799-5808. [CrossRef]

78. Wu, K.; Li, Z.; Tang, J.; Lv, X.; Wang, H.; Luo, R.; Liu, P.; Qian, L.; Zhang, S.; Yuan, S. Controllable defects implantation in MoS2 grown by chemical vapor deposition for photoluminescence enhancement. Nano Res. 2018, 11, 4123-4132. [CrossRef]

79. Ye, G.; Gong, Y.; Lin, J.; Li, B.; He, Y.; Pantelides, S.T.; Zhou, W.; Vajtai, R.; Ajayan, P.M. Defects Engineered Monolayer MoS 2 for Improved Hydrogen Evolution Reaction. Nano Lett. 2016, 16, 1097-1103. [CrossRef]

80. Yang, Y.; Chen, T.; Sumona, M.; Gupta, B.S.; Sun, Y.; Hu, Z.; Zhan, X. Utilization of iron sulfides for wastewater treatment: A critical review. Rev. Environ. Sci. Biotechnol. 2017, 16, 289-308. [CrossRef]

81. Bhattacharjee, S. Iron sulfide nanoparticles prepared using date seed extract: Green synthesis, characterization and potential application for removal of ciprofloxacin and chromium. Powder Technol. 2021, 380, 219-228. [CrossRef]

82. Gong, Y.; Huang, Y.; Wang, M.; Liu, F.; Zhang, T. Application of Iron-Based Materials for Remediation of Mercury in Water and Soil. Bull. Environ. Contam. Toxicol. 2019, 102, 721-729. [CrossRef] [PubMed]

83. Calagui, M.J.C.; Senoro, D.B.; Kan, C.-C.; Salvacion, J.W.L.; Futalan, C.M.; Wan, M.-W. Adsorption of indium(III) ions from aqueous solution using chitosan-coated bentonite beads. J. Hazard. Mater. 2014, 277, 120-126. [CrossRef] [PubMed]

84. Sun, M.; Cheng, G.; Ge, X.; Chen, M.; Wang, C.; Lou, L.; Xu, X. Aqueous Hg(II) immobilization by chitosan stabilized magnetic iron sulfide nanoparticles. Sci. Total Environ. 2018, 621, 1074-1083. [CrossRef]

85. Song, X.; Ke, F.; Ge, C.; Zhang, J.; Li, S.; Li, C.; Li, J. Core-Shell Magnetic Fe ${ }_{3} \mathrm{O}_{4} @ Z$ ZnS Nanoparticles As Highly Efficient Adsorbents for the Removal of Pb2+ from Water. Russ. J. Phys. Chem. A 2019, 93, 522-527. [CrossRef]

86. Maity, J.; Ray, S.K. Chitosan based nano composite adsorbent-Synthesis, characterization and application for adsorption of binary mixtures of $\mathrm{Pb}(\mathrm{II})$ and $\mathrm{Cd}(\mathrm{II})$ from water. Carbohydr. Polym. 2018, 182, 159-171. [CrossRef] [PubMed] 
87. Wang, X.; Xu, J.; Liu, J.; Liu, J.; Xia, F.; Wang, C.; Dahlgren, R.A.; Liu, W. Mechanism of Cr (VI) removal by magnetic greigite/biochar composites. Sci. Total Environ. 2020, 700, 134414. [CrossRef] [PubMed]

88. Yan, L.; Kong, L.; Qu, Z.; Li, L.; Shen, G. Magnetic Biochar Decorated with ZnS Nanocrytals for Pb (II) Removal. ACS Sustain. Chem. Eng. 2015, 3, 125-132. [CrossRef]

89. Duan, J.; Ji, H.; Liu, W.; Zhao, X.; Han, B.; Tian, S.; Zhao, D. Enhanced immobilization of U(VI) using a new type of FeS-modified $\mathrm{Fe} 0$ core-shell particles. Chem. Eng. J. 2019, 359, 1617-1628. [CrossRef]

90. Tan, C.; Dong, Y.; Fu, D.; Gao, N.; Ma, J.; Liu, X. Chloramphenicol removal by zero valent iron activated peroxymonosulfate system: Kinetics and mechanism of radical generation. Chem. Eng. J. 2018, 334, 1006-1015. [CrossRef]

91. Zhang, H.; Peng, L.; Chen, A.; Shang, C.; Lei, M.; He, K.; Luo, S.; Shao, J.; Zeng, Q. Chitosan-stabilized FeS magnetic composites for chromium removal: Characterization, performance, mechanism, and stability. Carbohydr. Polym. 2019, 214, $276-285$. [CrossRef] [PubMed]

92. Tian, S.; Gong, Y.; Ji, H.; Duan, J.; Zhao, D. Efficient removal and long-term sequestration of cadmium from aqueous solution using ferrous sulfide nanoparticles: Performance, mechanisms, and long-term stability. Sci. Total Environ. 2020, 704, 135402. [CrossRef]

93. Shi, T.; Yang, D.; Yang, H.; Ye, J.; Cheng, Q. Preparation of chitosan crosslinked modified silicon material and its adsorption capability for chromium(VI). Appl. Clay Sci. 2017, 142, 100-108. [CrossRef]

94. Kong, L.; Li, Z.; Huang, X.; Huang, S.; Sun, H.; Liu, M.; Li, L. Efficient removal of Pb(II) from water using magnetic Fe $3 \mathrm{~S}_{4} / \mathrm{reduced}$ graphene oxide composites. J. Mater. Chem. A 2017, 5, 19333-19342. [CrossRef]

95. Su, Y.; Adeleye, A.S.; Huang, Y.; Sun, X.; Dai, C.; Zhou, X.; Zhang, Y.; Keller, A.A. Simultaneous removal of cadmium and nitrate in aqueous media by nanoscale zerovalent iron (nZVI) and Au doped nZVI particles. Water Res. 2014, 63, 102-111. [CrossRef]

96. Du, J.; Bao, J.; Lu, C.; Werner, D. Reductive sequestration of chromate by hierarchical FeS@Fe-0 particles. Water Res. 2016, 102, 73-81. [CrossRef]

97. Li, Y.; Liang, J.; He, X.; Zhang, L.; Liu, Y. Kinetics and mechanisms of amorphous FeS2 induced Cr(VI) reduction. J. Hazard. Mater. 2016, 320, 216-225. [CrossRef] [PubMed]

98. Ray, S.S.; Gusain, R.; Kumar, N. Carbon nanomaterials: Synthesis, functionalization, and properties. In Carbon Nanomaterial-Based Adsorbents for Water Purification; Elsevier: Amsterdam, The Netherlands, 2020; pp. 137-179. [CrossRef]

99. Wu, Z.; Duan, Q.; Li, X.; Li, J. Mutual effects behind the simultaneous removal of toxic metals and cationic dyes by interlayerexpanded MoS 2 nanosheets. Environ. Sci. Pollut. Res. 2019, 26, 31344-31353. [CrossRef]

100. Jain, K.; Patel, A.S.; Pardhi, V.P.; Flora, S.J.S. Nanotechnology in wastewater management: A new paradigm towards wastewater treatment. Molecules 2021, 26, 1797. [CrossRef]

101. Zhao, Y.; Tian, S.; Gong, Y.; Zhao, D. Efficient Removal of Lead from Water Using Stabilized Iron Sulfide Nanoparticles: Effectiveness and Effects of Stabilizer. Water Air Soil Pollut. 2019, 230, 115. [CrossRef]

102. Pasinszki, T.; Krebsz, M.; Chand, D.; Kótai, L.; Homonnay, Z.; Sajó, I.E.; Váczi, T. Carbon microspheres decorated with iron sulfide nanoparticles for mercury(II) removal from water. J. Mater. Sci. 2020, 55, 1425-1435. [CrossRef]

103. El-Sayed, M.E. Nanoadsorbents for water and wastewater remediation. Sci. Total Environ. 2020, 739, 139903. [CrossRef]

104. Wang, Z.; Zhu, W.; Qiu, Y.; Yi, X.; von dem Bussche, A.; Kane, A.; Gao, H.; Koski, K.; Hurt, R. Biological and environmental interactions of emerging two-dimensional nanomaterials. Chem. Soc. Rev. 2016, 45, 1750-1780. [CrossRef]

105. Wang, Z.; Sim, A.; Urban, J.J.; Mi, B. Removal and recovery of heavy metal ions by two-dimensional MoS2 nanosheets: Performance and mechanisms. Environ. Sci. Technol. 2018, 52, 9741-9748. [CrossRef] [PubMed]

106. Chen, Y.; Liang, W.; Li, Y.; Wu, Y.; Chen, Y.; Xiao, W.; Zhao, L.; Zhang, J.; Li, H. Modification, application and reaction mechanisms of nano-sized iron sulfide particles for pollutant removal from soil and water: A review. Chem. Eng. J. 2019, 362, 144-159. [CrossRef]

107. Zhu, K.; Chen, C.; Xu, H.; Gao, Y.; Tan, X.; Alsaedi, A.; Hayat, T. Cr(VI) Reduction and Immobilization by Core-DoubleShell Structured Magnetic Polydopamine@Zeolitic Idazolate Frameworks-8 Microspheres. ACS Sustain. Chem. Eng. 2017, 5, 6795-6802. [CrossRef]

108. Goodenough, J.B.; Manoharan, R.; Paranthaman, M. Surface protonation and electrochemical activity of oxides in aqueous solution. J. Am. Chem. Soc. 1990, 112, 2076-2082. [CrossRef]

109. van Koetsem, F.; van Havere, L.; Laing, G.D. Impact of carboxymethyl cellulose coating on iron sulphide nanoparticles stability, transport, and mobilization potential of trace metals present in soils and sediment. J. Environ. Manag. 2016, 168, $210-218$. [CrossRef] [PubMed]

110. Gong, Y.; Liu, Y.; Xiong, Z.; Zhao, D. Immobilization of mercury by carboxymethyl cellulose stabilized iron sulfide nanoparticles: Reaction mechanisms and effects of stabilizer and water chemistry. Environ. Sci. Technol. 2014, 48, 3986-3994. [CrossRef] [PubMed]

111. Sun, Y.; Lou, Z.; Yu, J.; Zhou, X.; Lv, D.; Zhou, J.; Baig, S.A.; Xu, X. Immobilization of mercury (II) from aqueous solution using Al2O3-supported nanoscale FeS. Chem. Eng. J. 2017, 323, 483-491. [CrossRef]

112. Wang, M. Immobilization of mercury by iron sulfide nanoparticles alters mercury speciation and microbial methylation in contaminated groundwater. Chem. Eng. J. 2020, 381, 12264. [CrossRef]

113. Kamba, Y.; Ueta, M.; Uddin, M.A.; Kato, Y. Enhancement of Zinc Ion Removal from Water by Physically Mixed Particles of Iron/Iron Sulfide. Water Air Soil Pollut. 2021, 232, 17. [CrossRef] 
114. Siyal, A.A.; Shamsuddin, M.R.; Khan, M.I.; Rabat, N.E.; Zulfiqar, M.; Man, Z.; Siame, J.; Azizli, K.A. A review on geopolymers as emerging materials for the adsorption of heavy metals and dyes. J. Environ. Manag. 2018, 224, 327-339. [CrossRef]

115. Liu, L.-N.; Dai, J.-G.; Zhao, T.-J.; Guo, S.-Y.; Hou, D.-S.; Zhang, P.; Shang, J.; Wang, S.; Han, S. A novel Zn(II) dithiocarbamate/ZnS nanocomposite for highly efficient $\mathrm{Cr}^{6+}$ removal from aqueous solutions. RSC Adv. 2017, 7, 35075-35085. [CrossRef]

116. Lee, J. Facile fabrication of $\mathrm{Cu}$-exchanged $\mathrm{ZnS}$ nanoadsorbents for highly efficient removal of contaminants. J. Environ. Chem. Eng. 2017, 5, 4431-4440. [CrossRef]

117. Li, C. Facile synthesis of nano $\mathrm{ZnO} / \mathrm{ZnS}$ modified biochar by directly pyrolyzing of zinc contaminated corn stover for $\mathrm{Pb}(\mathrm{II})$, $\mathrm{Cu}(\mathrm{II})$ and $\mathrm{Cr}(\mathrm{VI})$ removals. Waste Manag. 2018, 79, 625-637. [CrossRef]

118. Wang, C.; Yin, H.; Bi, L.; Su, J.; Zhang, M.; Lyu, T.; Cooper, M.; Pan, G. Highly efficient and irreversible removal of cadmium through the formation of a solid solution. J. Hazard. Mater. 2020, 384, 121461. [CrossRef] [PubMed]

119. Alamolhodaei, N.; Eshghi, H.; Massoudi, H. Nano-sized ZnS functionalized with dioxa-dithio ligands for removal of $\mathrm{Pb}(\mathrm{II}) \mathrm{from}$ aqueous solution. Inorg. Nano Met. Chem. 2019, 49, 100-106. [CrossRef]

120. Malakar, A.; Das, B.; Sengupta, S.; Acharya, S.; Ray, S. ZnS nanorod as an efficient heavy metal ion extractor from water. J. Water Process Eng. 2014, 3, 74-81. [CrossRef]

121. Jia, F.; Zhang, X.; Song, S. AFM study on the adsorption of $\mathrm{Hg}^{2+}$ on natural molybdenum disulfide in aqueous solutions. Phys. Chem. Chem. Phys. 2017, 19, 3837-3844. [CrossRef]

122. Zhi, L.; Zuo, W.; Chen, F.; Wang, B. 3D MoS 2 Composition Aerogels as Chemosensors and Adsorbents for Colorimetric Detection and High-Capacity Adsorption of $\mathrm{Hg}^{2+}$. ACS Sustain. Chem. Eng. 2016, 4, 3398-3408. [CrossRef]

123. Aghagoli, M.J.; Beyki, M.H.; Shemirani, F. Application of dahlia-like molybdenum disulfide nanosheets for solid phase extraction of Co(II) in vegetable and water samples. Food Chem. 2017, 223, 8-15. [CrossRef]

124. Wang, Z.; Zhang, J.; Wen, T.; Liu, X.; Wang, Y.; Yang, H.; Sun, J.; Feng, J.; Dong, S.; Sun, J. Highly effective remediation of $\mathrm{Pb}(\mathrm{II})$ and $\mathrm{Hg}(\mathrm{II})$ contaminated wastewater and soil by flower-like magnetic MoS2 nanohybrid. Sci. Total Environ. 2020, 699, 134341. [CrossRef]

125. Tan, L.; Liu, Y.; Meng, F.; Wu, P.; Xia, Y.; Tang, Y. 3D hierarchical defect-rich C@MoS 2 nanosheet arrays developed on montmorillonite with enhanced performance in $\mathrm{Pb}(\mathrm{II})$ removal. Environ. Sci. Nano 2020, 7, 3088-3099. [CrossRef]

126. Cai, W.; Dionysiou, D.D.; Fu, F.; Tang, B. CTAB-intercalated molybdenum disulfide nanosheets for enhanced simultaneous removal of $\mathrm{Cr}(\mathrm{VI})$ and $\mathrm{Ni}(\mathrm{II})$ from aqueous solutions. J. Hazard. Mater. 2020, 396, 122728. [CrossRef]

127. Zhao, X.; Li, J.; Mu, S.; He, W.; Zhang, D.; Wu, X.; Wang, C.; Zeng, H. Efficient removal of mercury ions with MoS2-nanosheetdecorated PVDF composite adsorption membrane. Environ. Pollut. 2021, 268, 115705. [CrossRef]

128. Huang, S.; You, Z.; Jiang, Y.; Zhang, F.; Liu, K.; Liu, Y.; Chen, X.; Lv, Y. Fabrication of Ultrathin MoS2 Nanosheets and Application on Adsorption of Organic Pollutants and Heavy Metals. Processes 2020, 8, 504. [CrossRef]

129. Fu, W.; Ji, G.; Chen, H.; Yang, S.; Yang, H.; Guo, B.; Huang, Z. Engineering Anion Resin based Amorphous Molybdenum Sulphide Composite for Treatment of Authentic Acid Mine Drainage. J. Environ. Chem. Eng. 2020, 8, 104072. [CrossRef]

130. Li, X.; Li, Q.; Linghu, W.; Shen, R.; Zhao, B.; Dong, L.; Alsaedi, A.; Hayat, T.; Wang, J.; Liu, J. Sorption properties of U(VI) and $\mathrm{Th}(\mathrm{IV})$ on two-dimensional Molybdenum Disulfide (MoS2) nanosheets: Effects of $\mathrm{pH}$, ionic strength, contact time, humic acids and temperature. Environ. Technol. Innov. 2018, 11, 328-338. [CrossRef]

131. Sun, H.; Wu, T.; Zhang, Y.; Ng, D.H.; Wang, G. Structure-enhanced removal of Cr (vi) in aqueous solutions using MoS 2 ultrathin nanosheets. New J. Chem. 2018, 42, 9006-9015. [CrossRef]

132. Chen, H.; Chen, Z.; Zhao, G.; Zhang, Z.; Xu, C.; Liu, Y.; Chen, J.; Zhuang, L.; Haya, T.; Wang, X. Enhanced adsorption of U(VI) and $241 \mathrm{Am}(\mathrm{III})$ from wastewater using Ca/Al layered double hydroxide@carbon nanotube composites. J. Hazard. Mater. 2018, 347, 67-77. [CrossRef]

133. Hu, B.; Hu, Q.; Li, X.; Pan, H.; Tang, X.; Chen, C.; Huang, C. Rapid and highly efficient removal of Eu(III) from aqueous solutions using graphene oxide. J. Mol. Liq. 2017, 229, 6-14. [CrossRef]

134. Wang, J.; Zhang, R.; Huo, Y.; Ai, Y.; Gu, P.; Wang, X.; Li, Q.; Yu, S.; Chen, Y.; Yu, Z. Efficient elimination of Cr (VI) from aqueous solutions using sodium dodecyl sulfate intercalated molybdenum disulfide. Ecotoxicol. Environ. Saf. 2019, 175, 251-262. [CrossRef]

135. Liu, C.; Jia, F.; Wang, Q.; Yang, B.; Song, S. Two-dimensional molybdenum disulfide as adsorbent for high-efficient Pb(II) removal from water. Appl. Mater. Today 2017, 9, 220-228. [CrossRef]

136. Jia, F.; Liu, C.; Yang, B.; Zhang, X.; Yi, H.; Ni, J.; Song, S. Thermal Modification of the Molybdenum Disulfide Surface for Tremendous Improvement of $\mathrm{Hg}^{2+}$ Adsorption from Aqueous Solution. ACS Sustain. Chem. Eng. 2018, 6, 9065-9073. [CrossRef]

137. Feng, B.; Yao, C.; Chen, S.; Luo, R.; Liu, S.; Tong, S. Highly efficient and selective recovery of Au(III) from a complex system by molybdenum disulfide nanoflakes. Chem. Eng. J. 2018, 350, 692-702. [CrossRef]

138. Chen, B.; Bi, H.; Ma, Q.; Tan, C.; Cheng, H.; Chen, Y.; He, X.; Sun, L.; Lim, T.-T.; Huang, L.; et al. Preparation of graphene-MoS2 hybrid aerogels as multifunctional sorbents for water remediation. Sci. China Mater. 2017, 60, 1102-1108. [CrossRef]

139. Pandey, S.; Fosso-Kankeu, E.; Spiro, M.J.; Waanders, F.; Kumar, N.; Ray, S.S.; Kim, J.; Kang, M. Equilibrium, kinetic, and thermodynamic studies of lead ion adsorption from mine wastewater onto MoS2-clinoptilolite composite. Mater. Today Chem. 2020, 18, 100376. [CrossRef]

140. Dong, L.; Yang, J.; Mou, Y.; Sheng, G.; Wang, L.; Linghu, W.; Asiri, A.M.; Alamry, K.A. Effect of various environmental factors on the adsorption of $\mathrm{U}(\mathrm{VI})$ onto biochar derived from rice straw. J. Radioanal. Nucl. Chem. 2017, 314, 377-386. [CrossRef] 
141. Wang, P.; Yin, L.; Wang, J.; Xu, C.; Liang, Y.; Yao, W.; Wang, X.; Yu, S.; Chen, J.; Sun, Y.; et al. Superior immobilization of U(VI) and 243Am(III) on polyethyleneimine modified lamellar carbon nitride composite from water environment. Chem. Eng. J. 2017, 326, 863-874. [CrossRef]

142. Peng, W.; Li, H.; Liu, Y.; Song, S. A review on heavy metal ions adsorption from water by graphene oxide and its composites. J. Mol. Liq. 2017, 230, 496-504. [CrossRef]

143. Zhuang, Y.-T.; Zhang, X.; Wang, D.-H.; Yu, Y.-L.; Wang, J.-H. Three-dimensional molybdenum disulfide/graphene hydrogel with tunable heterointerfaces for high selective $\mathrm{Hg}$ (II) scavenging. J. Colloid Interface Sci. 2018, 514, 715-722. [CrossRef]

144. Guo, J.; Tian, H.; He, J. Integration of CuS nanoparticles and cellulose fibers towards fast, selective and efficient capture and separation of mercury ions. Chem. Eng. J. 2021, 408, 127336. [CrossRef]

145. Van der Stam, W.; Gudjonsdottir, S.; Evers, W.H.; Houtepen, A.J. Switching between Plasmonic and Fluorescent Copper Sulfide Nanocrystals. J. Am. Chem. Soc. 2017, 139, 13208-13217. [CrossRef] [PubMed]

146. Yao, C.; Chen, S.; Wang, L.; Deng, H.; Tong, S. Low cost and rapid fabrication of copper sulfides nanoparticles for selective and efficient capture of noble metal ions. Chem. Eng. J. 2019, 373, 1168-1178. [CrossRef]

147. Wang, T.; Zhang, H.; Xu, L.; Wang, X.; Chen, M. Laser-induced photochemical synthesis of fibrous-shaped CuO@CuS nanoporous structures for enhanced electrostatic adsorption of negatively charged contaminants from wastewater. Opt. Mater. Express 2017, 7, 3863. [CrossRef]

148. Ray, C. Evolution of tubular copper sulfide nanostructures from copper(i)-metal organic precursor: A superior platform for the removal of $\mathrm{Hg}(\mathrm{ii})$ and $\mathrm{Pb}(\mathrm{ii})$ ions. RSC Adv. 2015, 5, 12446-12453. [CrossRef]

149. Sharifpour, E.; Khafri, H.Z.; Ghaedi, M.; Asfaram, A.; Jannesar, R. Isotherms and kinetic study of ultrasound-assisted adsorption of malachite green and $\mathrm{Pb} 2+$ ions from aqueous samples by copper sulfide nanorods loaded on activated carbon: Experimental design optimization. Ultrason. Sonochem. 2018, 40,373-382. [CrossRef]

150. Hu, M.; Tian, H.; He, J. Unprecedented Selectivity and Rapid Uptake of CuS Nanostructures toward Hg(II) Ions. ACS Appl. Mater. Interfaces 2019, 11, 19200-19206. [CrossRef] [PubMed]

151. Cantu, J.; Valle, J.; Flores, K.; Gonzalez, D.; Valdes, C.; Lopez, J.; Padilla, V.; Alcoutlabi, M.; Parsons, J. Investigation into the thermodynamics and kinetics of the binding of $\mathrm{Cu} 2+$ and $\mathrm{Pb} 2+$ to TiS2 nanoparticles synthesized using a solvothermal process. $J$. Environ. Chem. Eng. 2019, 7, 103463. [CrossRef]

152. Zhang, J.; Yu, L.; Lou, X.W.D. Embedding CoS2 nanoparticles in N-doped carbon nanotube hollow frameworks for enhanced lithium storage properties. Nano Res. 2017, 10, 4298-4304. [CrossRef]

153. Andrea, J.; Santana, W.; Santos, N.L.; Silva, L.O.B.; Virgens, C.F. Removal of mercury(II) ions in aqueous solution using the peel biomass of Pachira aquatica Aubl: Kinetics and adsorption equilibrium studies. Environ. Monit. Assess. 2016, 188, 293. [CrossRef]

154. Raj, R.; Dalei, K.; Chakraborty, J.; Das, S. Extracellular polymeric substances of a marine bacterium mediated synthesis of CdS nanoparticles for removal of cadmium from aqueous solution. J. Colloid Interface Sci. 2016, 462, 166-175. [CrossRef] [PubMed]

155. Jiang, T.; Liu, W.; Mao, Y.; Zhang, L.; Cheng, J.; Gong, M.; Zhao, H.; Dai, L.; Zhang, S.; Zhao, Q. Adsorption behavior of copper ions from aqueous solution onto graphene oxide-CdS composite. Chem. Eng. J. 2015, 259, 603-610. [CrossRef]

156. Golkhah, S.; Mousavi, H.Z.; Shirkhanloo, H.; Khaligh, A. Removal of Pb(II) and Cu(II) Ions from Aqueous Solutions by Cadmium Sulfide Nanoparticles. Int. J. Nanosci. Nanotechnol. 2017, 13, 105-117.

157. Ghani, N.R.N.A.; Jami, M.S.; Alam, M.Z. The role of nanoadsorbents and nanocomposite adsorbents in the removal of heavy metals from wastewater: A review and prospect. Pollution 2021, 7, 153-179.

158. Kurniawan, T.A.; Sillanpää, M.E.; Sillanpää, M. Nanoadsorbents for remediation of aquatic environment: Local and practical solutions for global water pollution problems. Crit. Rev. Environ. Sci. Technol. 2012, 42, 1233-1295. [CrossRef] 